\title{
A Vision of Quantitative Imaging Technology for Validation of Advanced Flight Technologies
}

\author{
Thomas J. Horvath ${ }^{*}$, Robert V. Kerns ${ }^{\dagger}$, Kenneth M. Jones ${ }^{*}$ \\ NASA Langley Research Center, Hampton VA 23681 \\ Jay H. Grinstead ${ }^{\S}$ \\ NASA Ames Research Center, Moffett Field, CA 94035 \\ Richard J. Schwartz ${ }^{* *}$ \\ Analytic Mechanics Associates Inc., Hampton, VA 23681 \\ David M. Gibson ${ }^{\dagger}$, and Jeff C. Taylor ${ }^{*}$ \\ Johns Hopkins University Applied Physics Laboratory, Laurel, MD 20723 \\ Steve Tack ${ }^{\S}$ \\ Naval Air Warfare Center - Weapons Division, Pt. Mugu, CA 93042 \\ Ronald F. Dantowitz ${ }^{* * *}$ \\ Celestial Computing Inc., Brookline, MA 02467
}

\begin{abstract}
Flight-testing is traditionally an expensive but critical element in the development and ultimate validation and certification of technologies destined for future operational capabilities. Measurements obtained in relevant flight environments also provide unique opportunities to observe flow phenomenon that are often beyond the capabilities of ground testing facilities and computational tools to simulate or duplicate. However, the challenges of minimizing vehicle weight and internal complexity as well as instrumentation bandwidth limitations often restrict the ability to make high-density, in-situ measurements with discrete sensors. Remote imaging offers a potential opportunity to noninvasively obtain such flight data in a complementary fashion. The NASA Hypersonic Thermodynamic Infrared Measurements Project has demonstrated such a capability to obtain calibrated thermal imagery on a hypersonic vehicle in flight. Through the application of existing and accessible technologies, the acreage surface temperature of the Shuttle lower surface was measured during reentry. Future hypersonic cruise vehicles, launcher configurations and reentry vehicles will, however, challenge current remote imaging capability. As NASA embarks on the design and deployment of a new Space Launch System architecture for access beyond earth orbit (and the commercial sector focused on low earth orbit), an opportunity exists to implement an imagery system and its supporting infrastructure that provides sufficient flexibility to incorporate changing technology to address the future needs of the flight test community. A long term vision is offered that supports the application of advanced multi-waveband sensing technology to aid in the development of future aerospace systems and critical technologies to enable highly responsive vehicle operations across the aerospace continuum, spanning launch, reusable space access and global reach. Motivations for development of an Agency level imagery-based measurement capability to support cross cutting applications that span the Agency mission directorates as well as meeting potential needs of the commercial sector and national interests of the Intelligence, Surveillance and Reconnaissance community are explored. A recommendation is made for an assessment study to baseline current imaging technology including the identification of future mission requirements. Development of requirements fostered by the applications suggested in this paper would be used to identify technology gaps and direct roadmapping for implementation of an affordable and sustainable next generation sensor/platform system.
\end{abstract}

\footnotetext{
*Aerospace Engineer, LaRC Aerothermodynamics Branch, AIAA Associate Fellow.

${ }^{\dagger}$ Manager, LaRC Space Operations Project Office \& HYTHIRM

* Aerospace Engineer, LaRC Exploration \& Space Operation Directorate, AIAA Senior Member

$\S$ Aerospace Engineer, ARC Aerothermodynamics Branch, AIAA Associate Fellow.

${ }^{* *}$ Researcher, supporting LaRC Advanced Sensing and Optical Measurements Branch, AIAA Senior Member.

${ }^{\dagger}$ Principal Professional Staff, Applied Physics Laboratory, JHU, AIAA Member.

\# Senior Professional Staff, Applied Physics Laboratory, JHU, AIAA Senior Member.

$\S \S$ Imaging Specialist, Cast Glance, AIAA Member.

${ }^{* * *}$ Imaging Specialist, Mobile Aerospace Reconnaissance System (MARS), Celestial Computing, AIAA Member
}

1

American Institute of Aeronautics and Astronautics

This material is declared a work of the U.S. Government and is not subject to copyright protection in the United States. 


\section{Nomenclature}

$\begin{array}{ll}M & \text { freestream Mach number } \\ \mathrm{nm} & \text { nautical miles } \\ T & \text { surface temperature, deg F }\end{array}$

\section{Acronyms}

$\begin{array}{ll}\text { AFOSR } & \text { Air Force Office of Scientific Research } \\ \text { AHW } & \text { Advanced Hypersonic Weapon } \\ \text { ARMD } & \text { NASA Aeronautics Research Mission Directorate } \\ \text { ATV } & \text { ESA Automated Transfer Vehicle } \\ \text { BEO } & \text { Beyond Earth Orbit } \\ \text { BLT } & \text { Boundary Layer Transition } \\ \text { CCD } & \text { Charge Coupled Device } \\ \text { CCDev } & \text { NASA Commercial Crew Development } \\ \text { CFD } & \text { Computational Fluid Dynamics } \\ \text { CM } & \text { Command Module } \\ \text { COTS } & \text { NASA Commercial Orbital Transportation Services } \\ \text { CPAS } & \text { NASA CEV Parachute Assembly Project } \\ \text { C3PO } & \text { NASA Commercial Crew \& Cargo Program Office } \\ \text { DFI } & \text { Developmental Flight Instrumentation } \\ \text { DoD } & \text { U.S. Department of Defense } \\ \text { DARPA } & \text { U. S. Defense Advanced Research Project Agency } \\ \text { EDL } & \text { Entry Descent Landing } \\ \text { EELV } & \text { Evolved Expendable Launch Vehicle } \\ \text { ESA } & \text { European Space Agency } \\ \text { ESMD } & \text { NASA Exploration Systems Mission Directorate } \\ \text { ET } & \text { External Tank } \\ \text { GPS } & \text { Global Positioning Satellite } \\ \text { HYTHIRM } & \text { Hypersonic Thermodynamic Infrared Measurements } \\ \text { IR } & \text { Infrared } \\ \text { ISR } & \text { Intelligence Surveillance Reconnaissance } \\ \text { ISS } & \text { International Space Station } \\ \text { ISTEF } & \text { Innovative Sensor Evaluation Facility } \\ \text { LEO } & \text { Low Earth Orbit } \\ \text { LWIR } & \text { Long-Wave Infrared } \\ \text { MARS } & \text { Mobile Aerospace Reconnaissance System } \\ \text { MDA } & \text { Missile Defense Agency } \\ \text { MLAS } & \text { NESC Maximum Launch Abort System } \\ \text { MPCM } & \text { NASA Multi Purpose Crew Module } \\ \text { MWIR } & \text { Mid-Wave Infrared } \\ \text { NESC } & \text { NASA Engineering and Safety Center } \\ \text { NIR } & \text { Near Infrared } \\ \text { OCT } & \text { NASA Office Chief Technologist } \\ \text { PICA } & \text { Phenolic Impregnated Carbon Ablator } \\ \text { RTF } & \text { Return to Flight } \\ \text { SETI } & \text { Search for Extra-Terrestrial Intelligence (Institute) } \\ \text { SLS } & \text { Space Launch System } \\ \text { SMD } & \text { NASA Science Mission Directorate } \\ \text { SRB } & \text { Solid Rocket Booster } \\ \text { SSA } & \text { Space Situational Awareness } \\ \text { SSP } & \text { Space Shuttle Program } \\ \text { STS } & \text { Space Transportation System } \\ \text { SWIR } & \text { Short-Wave Infrared } \\ \text { TPS } & \text { Thermal Protection System } \\ \text { UAS } & \text { Unmanned Aerial System } \\ & \end{array}$




\section{Introduction}

Quantitative thermal imagery obtained by the Hypersonic Thermodynamic Infrared Measurements (HYTHIRM) team has provided a unique and never before observed perspective on the global distribution of surface temperature and the state of the boundary layer (i.e., laminar/turbulent) over the entire windward surface of the Shuttle during portions of hypersonic re-entry ${ }^{1-8}$. Sponsored by the Space Shuttle Program, observations made over a period of approximately 2.5 years spanning seven Shuttle missions have covered the Mach range from 6.2 to 18.1. The capability has been recently extended to include thermal observations (and complementary telemetry) on a commercial capsule reentry in 2010. This emerging quantitative thermal imaging capability represented several years of advocacy within the aerothermodynamics technical community, ${ }^{9}$ sponsorship by the NASA Engineering Safety Center $(\mathrm{NESC})^{10,11}$, and the Hypersonics Project within the NASA Aeronautics Research Mission Directorate (ARMD) ${ }^{9}$. The partnership resulted in methodical planning and mission execution by a coalition of NASA, Navy, government labs, and contractor personnel. The initial observation made in 2009 (STS-119) was intended to demonstrate the capability to collect scientific quality imagery in a reliable manner using available and accessible technology. To the author's knowledge, the 2011 Shuttle infrared (IR) observations near Mach 18 (STS-133) represents the highest speed at which calibrated thermal imagery has been obtained on a crewed maneuvering vehicle in the Earth's atmosphere that has sufficient spatial resolution to delineate local temperatures differences at various locations on the vehicle surface. The most recent thermally imagery at Mach 6.2 (STS-134) captured unique flow phenomenon never before observed in flight on a global scale at unprecedented spatial resolution. Collectively, thermal observations of Shuttle hypersonic re-entries from Mach 6 to 18 during seven missions, Fig. 1, were intended to provide the technical community with a unique source of flight data for reducing the uncertainty associated with present day ground-to-flight extrapolation techniques and current state-of-the-art computational prediction methods.

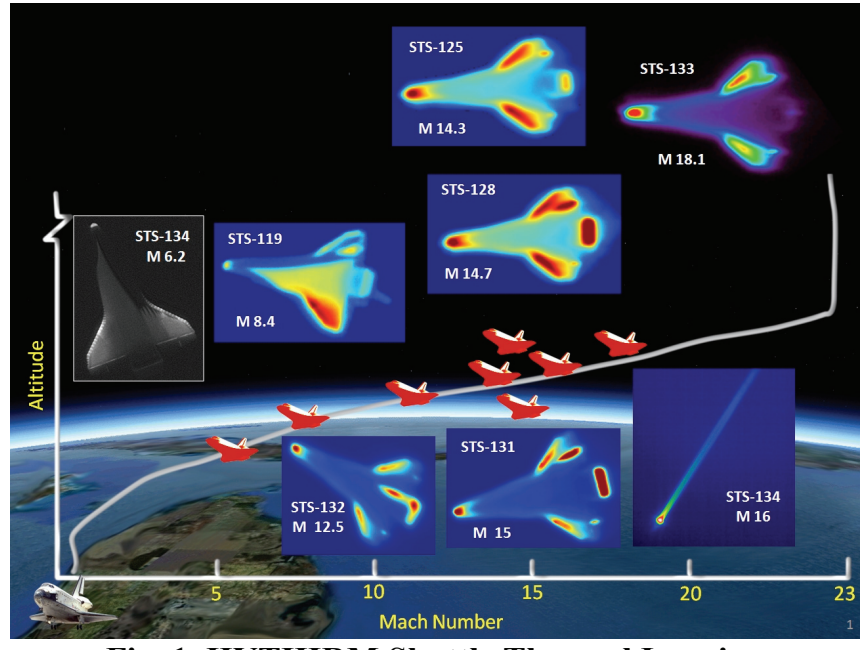

Fig. 1. HYTHIRM Shuttle Thermal Imaging Mach Envelope

While the people, hardware and strategy employed by HYTHIRM has been successful in measuring the acreage surface temperature of the Shuttle lower surface during reentry, future hypersonic cruise vehicles or advanced launcher configurations will likely challenge affordable remote imaging capability in terms of requirements (i.e., remote deployment locations, high speed tracking, spatial/spectral resolution and temperature sensitivity). The present paper seeks to expand upon the emerging thermal imaging capability demonstrated by the HYTHIRM team and explores the challenges and possibilities associated with developing a sustaining next generation imaging system capable of supporting a much broader range of requirements and mission objectives. Better observational datasets are necessary for supporting tool validation and understanding the limits of ground-to-flight traceability. A next generation imaging system would directly or indirectly support the development of critical enabling technologies including elements necessary for (but not limited to) hypersonic aerothermodynamics, high-temperature materials for thermal protection, flight dynamics and range safety including launch and reentry. In order to justify an investment of this nature, the use of imagery beyond a public relations tool must be examined. That is, if imagery is to continue to become an integral part of the engineering and operations process associated with the development of new aeronautical or aerospace systems then its potential role in the flight test process must be reflected upon. To this end, section II will present some perspectives on the nature of flight-testing. Motivations for imagery-based measurement and potential cross cutting applications are then identified in section III. To highlight existing capability and identify shortfalls, section IV provides a high level synopsis of a few recent observation campaigns that have provided visual, thermal or spectral flight data. Based upon the author's experiences, section $\mathrm{V}$ highlights a few specific flight test opportunities on the short-term horizon. Section VI suggest one possible long-term vision of an adaptive "smart" sensor configuration integrated to a ground or high altitude platform to further increase mission flexibility while reducing operational costs to acquire the scientific and engineering quality data. Finally, section VII presents a summary and a recommendation for an assessment study to (1) define current imaging technology 
capabilities, (2) identify mission requirements and the resulting technology gaps along with (3) a roadmap for a closing these gaps including a forward plan to develop a next generation sensor/platform system.

\section{Flight Testing}

Generally speaking, aircraft, spacecraft and weapons systems are fundamentally designed within a framework of analytical tools, wind tunnel testing, material testing, computational simulation and more often than not, ending with a flight test. Flight-testing represents a critical phase in the development process and ultimately in the validation and certification of technologies destined for future civilian and military operational capabilities ${ }^{12,13}$. Nowhere is this more evident than for vehicles operating in or traversing through the hypersonic speed regime. As is commonly recognized, hypersonic vehicles operate at flight conditions very different from their counterparts at subsonic or supersonic conditions. This poses additional challenges to the designer in the sense that material response, surface phenomenon and gas characteristics around the vehicle cannot necessarily be duplicated in any one laboratory or wind tunnel or necessarily simulated by numerical means. Flight testing is therefore imperative to engineers working the design of hypersonic vehicles as it provides the first set of insights from which to truly evaluate design assumptions, assess performance margins and ultimately better understand the nature of the weaknesses of database design tools. Measurements obtained in relevant flight environments also provide unique opportunities to observe flow phenomenon that represent the "unknown" unknowns. Historically, flight-testing spacecraft has required deorbiting or flying the vehicle to be evaluated into a predetermined test area and either recovering the test vehicle or recording data during reentry for subsequent recovery, or both. Precise targeting and de-orbiting of the reentry vehicle is required to assure safe return to the desired location. For example, the first five flights of the U.S. Space Shuttle were heavily instrumented with sensors and equipped with multiple data recorders to collect information on the heating environment and the performance of the Orbiter's thermal protection system. This type of instrumentation package, often referred to as Developmental Flight Instrumentation (DFI) naturally comes at the expense of added internal complexity, cost and schedule risk to the project. After the five developmental flights were completed, this extensive DFI sensor suite was removed from the Shuttle due to cost and weight penalties.

While nothing will completely replace the value of such in-situ instrumentation, the challenges of minimizing DFI impacts to vehicle weight and internal complexity as well as inherent instrument bandwidth limitations will always restrict the ability to make high spatial density in-situ measurements. Due to certification requirements, DFI instrumentation of the in-situ type is expensive, effectively limiting reentry research to government agencies and larger corporate institutions. In subsequent sections, the suggestion is offered that remote imaging could potentially offer an alternative or synergistic opportunity to noninvasively obtain unique and critical flight data without interfering with nominal vehicle operations, weight, performance and project scheduling. To underscore the importance of measurement associated with flight-testing and the challenges presented therein, examples are highlighted from three diverse technical communities.

The first example identifies a recent (and classic) example of the challenges faced with balancing the needs of the engineering community against stated project objectives. The NASA ARES I-X project developed a vehicle that served as a first stage prototype and a design concept demonstrator in the Ares I program, a proposed launch system for human spaceflight. Prior to its successful launch in 2009, a significant reduction in instrumentation (thermal, pressure, acoustic) was proposed presumably to reduce project costs and relieve schedule pressure. In response to pushback from the technical community, the NASA Engineering Safety Center (NESC) was asked to develop a position paper ${ }^{14}$ that detailed the possible technical implications and risks associated with the proposed reduction in DFI. In the final assessment document, the NESC panel recognized the paramount importance to the project objective of any flight test program - that is, a successful flight. However, they also concluded that when a flight test involves unique conditions (i.e., a new or extreme flight profile), an innovative vehicle design, or in the case of a developmental flight test laying the groundwork for future vehicle design that "every effort should be made to acquire engineering data for these flights so that the full value of them can be realized by the Agency and engineering community at large". As a result of the appeal from the technical community, the instrumentation on ARES 1-X was not removed. In section III, it is suggested that in general, flight data derived from quantitative imagery could assist in maximizing the return on investment of NASA flight testing by complementing, enhancing or in limited cases, replacing the traditional in-situ DFI measurement approach.

The second example illustrating the need for instrumentation is associated with a flight anomaly that resulted in the loss of the Hypersonic Test Vehicle (HTV-2) flown by DARPA and the U.S. Air Force in 2010. The experience underscores the criticality of adequate flight instrumentation in the event of a mishap. The Falcon HTV-2 is designed to glide through the Earth's atmosphere at speeds 20 times greater than the speed of sound paving the way for a precision payload delivery anywhere around the world to support national security interests. According to 
DARPA press releases ${ }^{15}$, the first flight was terminated approximately 9 minutes into the projected 30-minute flight. The demise of the test vehicle was initiated when onboard systems detected undesirable and unsafe flight behavior and forced the HTV-2 into a controlled descent into the ocean. As outlined in Ref. 16, a significant investment in ground-, sea-, air- and space-based assets was assembled to support this flight. Much of this investment was focused towards radar tracking and telemetry objectives. With limited instrumentation on the flight vehicle, a few assets with electro-optical imaging capabilities were also deployed. None of these assets however, were positioned or capable of providing thermal information of sufficient resolution to contribute to the analysis of the anomaly experienced in flight. In light of the mishap, it is quite possible that reconstruction of events could have proceeded at a more accelerated pace thus allowing the test team more time to prepare for the planned follow-on flight. It is suggested that a next generation imaging system could provide the necessary flexibility to satisfy the demanding requirements associated with a flight test conducted in the inherently remote locations of the nation's test ranges.

The third example highlighting instrumentation needs is derived from strategic planning associated with the Agency's Office of the Chief Technologist (OCT). NASA is presently developing a set of fourteen technology area roadmaps that it considers pathways to advance the nation's current capabilities. The objective of one of the draft roadmaps (TA-09: Entry, Descent and Landing Systems) ${ }^{17}$ is to recommend an overall technology investment strategy and prioritization of NASA's space technology activities that will enable future missions to destinations within our solar system. Missions of this nature will entail entry, decent, and landing (EDL) onto a planetary body and/or a possible transit through an atmosphere. As with the launch and hypersonic cruise vehicle examples cited previously, flight measurements provide a critical link between predicted and observed performance of an EDL system. One of the early conclusions of the EDL roadmap team was the criticality of acquiring performance data of these technologies in their flight environment in order to enable further development and use in later missions. Earth testing on the ground and in flight was recognized by the EDL team as the foundation of technology development and qualification. However, due to the expense of these developmental tests, EDL missions to date have instead largely relied on the technology developed and qualified in the 1960's and 1970's. In order to enable mission sets and science goals that may not be realizable based on current and near term evolving EDL technologies, the team recommended the need to invest in a vigorous program of new ground and flight-testing. Because major technical challenges exist in entry vehicle instrumentation, a dual investment strategy consisting of a sustained investment in traditional intrusive in-situ instrumentation development coupled with development of advanced remote observation platforms was suggested in the roadmap. One of the preliminary recommendations is the development of a NASA policy requiring a standard instrumentation package on all future planetary robotic probes to advance and build confidence in models that are essential to EDL system qualification. It is suggested that advanced optical and other non-intrusive measurement techniques could potentially provide such qualification data associated with advance entry, descent and landing concepts.

In summary, it is likely that flight-testing will continue to be integral to the development of future launch configurations, hypersonic cruise vehicles and reentry vehicles. These flight tests will require measurements to advance the state-of-the-art in design tools and/or reduce that margins required for a follow-on operational system. Arguably, these conclusions are equally applicable to the commercial sector now embarking on a path for development of system architectures for accessing low earth orbit and returning payloads (or crew) back to earth safely, reliably and economically. The next section of the paper provides a broad and high-level review of potential imagery applications that would have impact on our engineering capabilities and tools. This section is intended to foster the development of more detailed requirements that will eventually drive the design of a next generation imaging capability. In the remaining sections of this paper, a select review of recent observation campaigns are used to illustrate successful applications of existing capability to provide such flight data while identifying shortfalls in current remote imaging methods. The goal is to develop and communicate a vision that supports a long-term Agency strategy of applying advanced visual, thermal and spectral sensing technology to reduce uncertainties in design tools hence removing unnecessarily large thermal protection system (TPS) margins that currently translate to reduced payload capability and degraded mission performance.

\section{Imagery as an Important Engineering and Operations Tool}

Imagery is multi-faceted and can support a range of end-user requirements and functions. At the highest level, some of the most obvious within NASA include but are not limited to: real-time monitoring for safety and security; post-flight analysis to assure the safety of mission operations associated with subsequent flights; assessment/verification of vehicle performance; identification of in-flight anomalies or close calls and finally, mishap reconstruction. As the objective of this paper is to explore the utility of a next generation imaging system, it is relevant to first examine the historical role of imagery from the perspective of NASA. As discussed by Page in an 
unpublished 2006 white position paper ${ }^{18}$, imagery was initially an important engineering and operations tool for NASA. For example, NASA utilized a top down requirements approach that defined the use of ground-based (and on-board imagery) for the design and operational aspects of Saturn/Apollo program. Few can forget the dramatic footage of the Saturn V vehicle lifting off the pad on its journey to the moon. Evident in this footage is the alternating black/white paint scheme on the ascent stack and the shower of ice particulates falling away from the vehicle. Few may know that image analysts used the paint scheme to infer and provide engineers vehicle roll rates (a modified version of this painting scheme was later used on the ARES 1-X flight test vehicle). While generally not a safety of flight risk for Saturn, the issues posed by ice debris during launch would come back to challenge NASA during the Shuttle program. In sharp contrast to the Saturn experience, a top down system approach to imagery was not utilized during design of the U.S. Space Shuttle Program (SSP). Imagery was initially only identified as a requirement to satisfy public relations needs. As pointed out by Page, imagery based requirements were eventually added to support the SSP but more often than not, they were "added piecemeal in response to anomalous conditions discovered during operations". Introduced in this manner, the image analysts were often faced with data of insufficient quality (or no data) to meet the needs of the engineering community. This fact was most apparent during the Columbia Accident (STS-107) and subsequent Return-to-Flight (RTF) efforts. For example, the now common but still dramatic live video feeds of the Shuttle as it ascends into orbit, Fig. 2, was originally motivated by foam loss from the external tank on the very first flight (STS-1) in 1981. The cameras placed in the Orbiter's umbilical well as well as the infrastructure to transmit this information real time or during the flight (to provide the engineers foam loss data) took years to incorporate into the Shuttle fleet as is now routinely done with cameras placed on the Solid Rocket Boosters (SRB) and External Tank (ET). The general lack of a proactive approach to quantitative imagery - and equally important - the lack of defined requirements from the engineering community, are not limited to the SSP. In the opinion of the author, the challenge is somewhat still pervasive across the Agency. A paradigm shift must occur so that quantitative imagery is viewed as a required, rather than an optional, investment. Page concludes that this type of piecemeal approach has resulted in an imagery system within NASA that is largely compartmentalized across

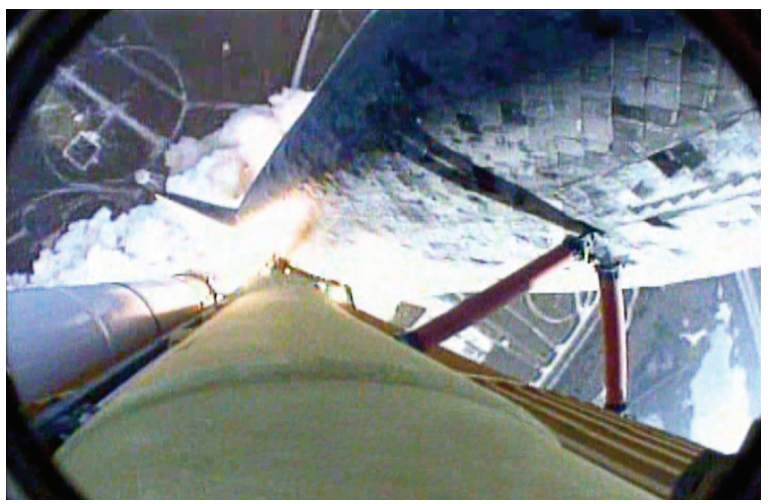

Fig. 2. Camera View During Shuttle Launch to Document Debris Events for Engineering Analysis. the Centers with marginal ability to respond to the needs of the engineering community and to adapt to technology improvements as they become available. In today's budget climate, a fractured, compartmentalized approach will likely not be successful and will most certainly not be cost effective. If each niche community were to design, construct, operate and maintain the necessary infrastructure (i.e., people, hardware/software and analysis tools) tailored to specific needs, then the complexity of an Agency level imagery system would become too complex, unmanageable and ultimately unaffordable and unsustainable.

As NASA embarks on the design and deployment of a new Space Launch System (SLS) architecture for access Beyond Earth Orbit (BEO) and the commercial sector focused on Low Earth Orbit (LEO), an opportunity exists to implement an approach to an imagery system and its supporting infrastructure that provides sufficient flexibility to incorporate changing technology to address the future needs of the flight test community. This approach has been successful in the Science Mission Directorate. NASA made a strategic investment in developing a unique airborne observatory referred to as the Stratospheric Observatory for Infrared Astronomy (SOFIA) ${ }^{19}$. The strength of SOFIA's architecture lies in its enormous breadth of astronomical capabilities and the flexibility with which those capabilities can be modified and improved to take advantage of advances in infrared technology. HYTHIRM advocates for a analogous Agency level vision supporting the application of an airborne system consisting of advanced visual, thermal and spectral sensing technology to aid in the development of future aerospace systems and critical technologies to enable highly responsive vehicle operations across the aerospace continuum, spanning launch, reusable/reliable space access and global reach (hypersonic cruise). Motivations for development of an Agency level imagery-based measurement capability that can potentially serve cross cutting applications across the Agency mission directorates as well as meeting potential needs of the commercial sector and national interests of the Intelligence, Surveillance and Reconnaissance (ISR) community are now explored. While not the focus of this paper, it should be recognized that the U.S. Department of Defense (DoD) and the Missile Defense Agency (MDA) have considerable investments in imagery ${ }^{20,21}$. Naturally, quantitative requirements associated with these organiza- 
tions are directed more towards target identification, lethality/hit determination, impact intensities, flash decay, debris cloud expansion/trajectories as well as nominal vehicle performance (i.e., ascent, intercept, staging, parachute recovery etc) and to aid mishap reconstruction. Limited capability exists in terms of a mobile asset to provide spatially resolved thermal imagery that is advocated for in this paper.

A secondary objective of this section is to suggest topic areas from which science and engineering requirements can be derived. Naturally, requirements derived from many of the applications described in the remainder of this section can presently be supported with available technologies while others require integration of higher end optics, sensors, and/or onboard processing algorithms (for target tracking or optimal sensor configuration) into existing or alternate platforms. The motivation and application themes are organized around thermal, spectral and visual imagery systems.

Thermal related applications: The flow phenomenon around a vehicle operating at or passing through the high Mach number regime dictates a thermal protection system to protect the crew and/or cargo. For launch vehicles the resulting aerothermodynamic issues can be different from those experienced by classical reentry (or cruise) type configurations. Mach number (compressibility) and Reynolds number (viscous/shear forces) are more relevant for ascent vehicles in contrast to high temperature real gas effects and pressure forces for reentry configurations. Relative to near constant conditions experienced by a hypersonic cruise vehicle, the local environment for a rocket changes continuously and rapidly during the critical few minutes when it moves from sea-level conditions to the edge of space. The maximum heat-transfer typically occurs high in the atmosphere when the velocity is greatest (but the density is low). Booster separation shocks, jet/plume impingements during staging, launch abort or attitude control maneuvers and complex flow around component attachment hardware can produce localized heating. In addition, booster plume radiation to the surrounding structure can also contribute to elevated heating. Large margins to protect against the uncertainties in surface temperature (coupled to static/dynamic pressure loads on ascent) can result in unnecessary structural and TPS mass. Ultimately, like their reentry counterparts, the weight of any thermal protection required on components associated with the climb to orbit represent a loss in vehicle performance. Optimizing the amount of insulation used on future launchers developed and operated by the emerging commercial sector will become vital because every pound of excess insulation reduces the payload capability of the vehicle. Getting the environments right will be critical if components are intended for re-use. Similar examples of temperature related design challenges existed with the now abandoned Constellation architecture. For example, a percentage of the structural weight of the proposed ARES V payload fairing (shroud) was required to protect the payload and sensitive internal equipment from heat generated by high-speed atmospheric flight during ascent. Similarly, on the ARES I launch configuration the total mass of a cork based TPS material covering the Orion capsule shroud was substantially increased due to uncertainties in the ascent environments. Global surface temperature measurements derived from calibrated thermal imagery on a launcher could permit the more accurate assessment of performance margins - and for the commercial sector, increased revenue on a payload mass basis. An affordable high altitude observation capability could potentially provide a view and quantitative data not obtainable with a ground platform (e.g., a closer view of the capsule/escape system during ascent with minimal atmospheric distortion or plume interference effects).

Industry also provides the DoD with launch services. The services are generally procured with a government-led process for acceptance, qualification, and certification of flight hardware. Currently, the DoD is evaluating options for upgrades or replacement of the current fleet of evolved expendable launch vehicles (EELV). Several studies suggest that significant cost savings can be achieved by evolving to a two-stage-to-orbit system with a reusable first stage that can achieve higher flight rates. As such, the DoD is pursuing a reusable first-stage booster and second stage to enable these additional cost savings. It is expected that complex flow phenomenon associated with a high supersonic/low hypersonic Mach number staging event would produce transient local heating. Accurate flight data would assist in determining the location of the heating footprint for TPS selection and sizing requirements. Presently, multi-band (i.e., mid-wave and long-wave) infrared imagery is commonly collected on many launches associated with the Delta IV and Atlas V systems using ground, air or space based imaging platforms. Thermal imagery associated with launches is hardly noteworthy; for several decades, the Missile Defense Agency has had a vested interest in target identification of a missile in the boost phase from a signature and tracking perspective. The engineering and modeling community have benefited from the collection of such infrared data that was initially prompted by a need to evaluate the reliability of theoretical models for rocket exhaust plume signatures and emissions. $^{22-24}$ More recently, launch imagery has focused on the objective of the identification of debris sources. NASA has invested considerable resources in ground assets for providing high-resolution visual imagery to detect debris during launch as the Shuttle stack leaves the pad. In addition, the U.S. Air Force has sponsored multiwaveband thermal imaging to quantify and characterize the presence of undesirable foreign material in the ascent 
plume $^{25}$. Relative intensity measurements are collected in a manner so as to infer the emissivity characteristics and hence likely material composition - of the debris to determine if an anomalous condition exists (i.e., if the material represents nozzle throat degradation or is merely benign material shed from the stack). Down range, debris detection and material identification becomes more difficult due to the extreme distances to the target using ground assets. As discussed in Ref. 24, such dual band sensor technology is primarily intended enhance battlefield situational awareness in all ambient conditions by locating and classifying threats with increased effectiveness over existing systems (i.e., more effective in defeating IR countermeasures such as smoke, camouflage, and flares). An affordable high altitude observation capability with such advanced detector technology could potentially provide a unique view of the thermal aspects complex staging events, qualification and certification of EELV hardware and the evaluation of exhaust plume structure, emission characteristics and debris identification at altitudes above the Earth's infrared-obscuring atmospheric water vapor and $\mathrm{CO}_{2}$.

The most obvious engineering application of calibrated thermal imagery relates to reentry. In general, heating augmentations and temperature increases resulting from hypersonic flight through the atmosphere of Earth (or other planets such as Mars) impose critical requirements on the design of any vehicle TPS. One of the largest drivers of these heating augmentations is boundary layer transition (BLT). The onset time and physical location of laminar-toturbulent transition and subsequent fully turbulent surface heating determine the thermal protection system material selection, placement, and thickness (i.e., vehicle design, weight, payload etc.). In terms of vehicle performance, boundary layer transition can influence vehicle aerodynamics (i.e., increased drag), landing (or impact) accuracy of autonomously guided spacecraft or delivery systems and scramjet propulsion system aerodynamic performance. The renewed interest in thermal imagery during Shuttle entry (Ref. 9) was initially motivated by the desire to reduce uncertainties associated with an empirical strategy to predict BLT onset ${ }^{26}$. This empirical methodology, adopted to quickly assess thermal environments induced by damage to the Shuttle's TPS, was derived from ground-based measurements that were extrapolated to flight using representative (and limited) flight data. The development of physics-based numerical tools for the reliable and rapid prediction of BLT, however, continues to be hindered by the inability to rapidly and accurately model the complex physics associated with this processes. Until the larger than desired uncertainties in prediction methods used to determine boundary layer transition onset times and surface temperatures from flow turbulence are reduced, unnecessarily large TPS margins will translate to reduced payload capability and degraded mission performance. In Reference ${ }^{27}$ Berry et. al., concludes the only viable alternative for allowing fundamental breakthroughs in our understanding of the transition process at hypersonic flight conditions is flight-testing. Berry indicates that executing such an endeavor would involve overcoming formidable challenges in the design and instrumentation of a test vehicle to yield the desired test conditions and high frequency transition data. Coupled to such surface instrumentation, an affordable high altitude thermal observation capability could potentially provide an unparalleled insight of the physical process of boundary layer transition in a high enthalpy flight environment free of disturbances that contaminate such measurements in ground-based wind tunnels.

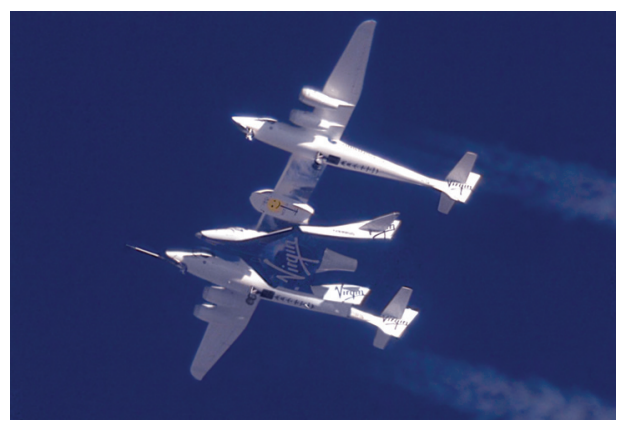

Fig. 3. Imagery Opportunities Associated with Sub Orbital Commercial Flight.

In contrast to returning from low earth orbit or beyond, suborbital reentry does not demand the level of thermal protection on the vehicle. While the relative thermal challenges may be lower, it has been recognized that these commercial vehicle platforms may provide unique, low cost flight research opportunities. It has been suggested by the National Center for Hypersonic Laminar-Turbulent Transition Research, a laboratory jointly sponsored by NASA and the Air Force Office of Scientific Research (AFOSR), to consider the use of these emerging commercial suborbital vehicles for research related to boundary layer transition. If the projected flight rates of these commercial entrepreneurs are realized, the possibility exists to obtain a large statistical dataset of when and where boundary layer transition onset occurs under high supersonic, low hypersonic flight conditions. The vehicle architecture with one of the commercial suborbital concepts requires the use of a high altitude aircraft to release a second vehicle intended to travel a ballistic trajectory to the edge of space, as shown in Fig. 3 - courtesy of Mobile Aerospace Reconnaissance System (MARS). Thermal observations performed from such a high altitude platform would serve as an ideal non-evasive measurement technique supporting an effort to monitor the BLT on the spacecraft (via temperature) during ascent and subsequent reentry. 
Spectral related applications: Spectral information is of equal importance to the engineering community. In particular, time-resolved high-resolution spectral data can be obtained in applications where high spatial resolution requirements cannot be achieved or are not desired. Hyperspectral imaging provides spatial information across a very large number of narrow but discrete spectral bands. Spectral measurement is useful in the identification of gas composition. An obvious application for measurements of this nature would be the characterization of exhaust plume signatures from a rocket or air-breathing hypersonic system from a signatures and/or environmental perspective. Similar to conclusions drawn from market assessments with rockets, current studies suggest that the economic viability of air-breathing systems is enabled through significantly higher flight rates in the context of requirements for responsive and flexible mission operations. It is documented that combustion emissions from rocket launches change the composition of the atmosphere. The changes can be classified into transient changes near the launch site that affect local air quality and long-term global changes in the composition of the upper stratosphere ${ }^{28}$. Carbon dioxide emissions from rocket engines are fairly well characterized and the resulting "carbon footprint" is small compared with other forms of transportation. Thus, space systems are not likely a significant contributor to climate change, even with an expanding space industry. However, Ross concludes ${ }^{28}$ that continual vigilance seems prudent. In contrast, the impacts of exhaust emissions from a rocket or air-breather on the ozone are largely unknown. Ross observes that very significant investments are being made in new launch and orbital systems without significant regard to how they affect the ozone. Hybrid propellant rockets and hypersonic scramjets are being developed and tested under the assumption of unlimited future use. Unfortunately, our understanding of how these systems may affect the ozone on a global scale is largely unknown. It has been suggested that management of this risk can be accomplished through investment in research to close the knowledge gaps regarding the effects of space transportation systems on the atmosphere and in particular, the ozone layer. It is therefore argued that development of an Agency level imagery-based measurement system could expand capability to this cross cutting environmental application (along with the NASA DC-8 and WB-57 platforms). Spectral imagery could be part of an arsenal of tools for characterizing aircraft (or rocket) emissions in flight. Emissions of interest include NOx, CO, CO2, unburned hydrocarbon fuels and particulates.

Quantitative (calibrated) narrow band spectral radiance can reveal the presence of excited state species resulting from shock-heated air or ablation products in the free stream and wake behind a reentering vehicle (or natural object such as a meteor). The detection of unintended species in the wake of a reentry vehicle can suggest an anomalous condition associated with TPS performance. An unpublished white paper by Johnston ${ }^{29}$ has suggested that insight into the aerothermodynamic environment of a high-speed Earth return vehicle (i.e., Mars return) may be gained through spectral observations of meteor entries. Vehicles returning to Earth from Mars may enter the atmosphere at velocities as high as $60 \mathrm{kft} / \mathrm{s}$. At these speeds, the structure of the shock layer is influenced significantly by radiative energy transport and massive surface ablation. These coupled radiation and ablation phenomena must be accurately modeled to predict the vehicle's aerothermodynamic environment during reentry. It is generally accepted that current modeling practices for state-of-the-art radiation prediction tools possess an uncertainty of $+/-75 \%$. Major components of this uncertainty include the turbulent mixing of ablation products, the absorption properties of ablation products, and the presence of a strong radiative precursor. The reduction of these uncertainty components is, in the near term, uncertain as no experimental data of this nature currently exists nor is likely to be produced in a ground based laboratories. Johnston suggests instrumented observations of meteor entries to obtain this critical data. Spectral measurements associated with meteors on the order of $0.3 \mathrm{ft}$ diameter traveling approximately 50-65 kft/sec at altitudes below $230,000 \mathrm{ft}$ could potentially fill a need for data associated with a coupled ablating-radiating flowfield.

Growing concerns on the effects of space debris on the cost of space operations has been the subject of recent work by the Aerospace Corporation ${ }^{30}$. There is an interest to collect information to characterize what happens to launch hardware that will reenter after a satellite or crewed vehicle is deployed (or the satellite itself that might reenter at the end of its mission). In both cases, the hazard posed by surviving debris from such events is of concern. Accordingly, identification of orbital debris and/or the demise of spacecraft hardware during reentry are at the forefront of Space Situational Awareness (SSA). Implications from collisions with on-orbit debris range from degraded solar panel performance to fatal strikes compromising the functionality of a satellite. The demise of large space structures, whether intended or not, has implications pertaining to local range safety and/or the general public. NASA has worked with the DoD on several occasions to observe from air-borne platforms the reentry and breakup of spacecraft and launch vehicle stages. These airborne observations were at times supplemented with ground-based optical and radar observations. Two recent observations occurred in 1998 and 2000 with the reentries of Ariane 503 and the Compton Gamma Ray Observatory, respectively. With limited flight data, large uncertainties still persist in correctly modeling the temporal and spatial break-up process and predicting the subsequent trajectory and landed 
footprint of debris that may reach to ground. When an explosive event is associated with breakup, ejection velocity and ballistic coefficient of surviving fragments are driving factors for debris footprint prediction or re-contact analysis (if a crewed vehicle is in proximity during disposal). As discussed by Ailer ${ }^{31}$, simulation tools used to estimate the ground hazard associated with reentries have been calibrated using limited data derived from visual evidence and analysis of recovered hardware. These analyses have indicated that there are areas where first-principles may not be well understood leading to predicted breakup altitudes that are higher than actually occur (accurate breakup altitude predictions are critical for estimating the length of the subsequent ground impact footprint, a critical factor in safety analyses). Given these uncertainties, it is desirable to collect data during an actual reentry and breakup of a rocket stage or other space hardware. In the demise of spent launch hardware, the aerodynamic and heating on the reentering vehicle will increase to the point where low melting point materials soften exposing adjacent structure to heating. The coupled thermal and mechanical loads eventually result in fragmentation. Time stamped spectral data can indentify when and where individual components are liberated via discriminating spectral signatures thus yielding a better understanding of the processes underlying the break-up of spacecraft. Three-dimensional debris field trajectories, a critical aspect of any safety related analysis, could be determined by triangulation from two co-located observation locations. Spectrographs working the near-UV, visible and near IR wavelengths could be part of an arsenal of instruments associated with a dedicated platform for characterizing altitude of explosion; identification of likely cause (e.g. fuel tank rupture) and resulting fragments; measurement of tumble rate of vehicle and fragments during re-entry; wake emissions and identification of ablation products; and the analysis of debris dispersions (reducing the uncertainties defining hazard areas).

Visual related applications: Arguably, remote visual imagery has the most appeal from a public relations perspective. That aside, engineering applications are numerous. Naturally, many of these uses overlap and complement the tasks outlined for thermal and spectral applications. Within the launch community, these uses include identification and trajectories of debris liberated during initial lift-off and subsequent first stage ascent, tower clearances, plume asymmetries and identification of thermal induced damage during liftoff, and initial vehicle roll characteristics. Mid course events include verification of staging events and relative positions of disposed and active stages (three-dimensional positions triangulated from dual observations). Late course events include upper stage separation (if applicable) and verification of launch shroud/fairing separation (if present). If any hardware is intended for recovery (i.e., lower stages or capsule post-mission), then high definition visual imagery is the key source of engineering data. Verification of parachute system performance including motor firing and deployment/inflation events for the mains and drogues is required. Validation data such as the relative motions associated with main chute cluster dynamics "dancing" and main chute breathing or "jellyfishing" is desirable for calibrating modeling tools used to assess the performance of future deceleration systems. Final water or land impact speed/angle can be inferred from visual imagery using several standard reference methods. Drop areas for parachute system qualification testing may not have sufficient (or any) ground to air coverage, so an affordable high altitude observation capability or a mobile ground system could potentially provide views of the complex sequence of the recovery process.

\section{Current Quantitative Imaging Applications}

This section highlights a few observation campaigns that were intended to provide complementary quantitative measurements to support a flight test, or in some cases, the observations were the only source of data. Where appropriate, identification of shortfalls is presented.

During the lifetime of the Shuttle program, several attempts were made to obtain calibrated thermal imagery of the Orbiter during reentry. As summarized by Horvath ${ }^{9}$, the early attempts at observations were largely unsuccessful suffering from challenges primarily associated with preflight planning, communications, hardware, tracking and the general inability to respond to inherent cross range uncertainties associated with a Shuttle reentry. The success rate of data collection by the HYTHIRM team at the close of the Shuttle program, are attributed to addressing these shortfalls via rigorous mission planning and operations ${ }^{8,7,3}$; trained and skilled asset personnel ${ }^{2}$; and advancements in infrared detector technology and image analysis techniques ${ }^{6}$. The use of a highly proficient crew on board a Navy aircraft has provided the flexibility required to respond to cross range (ground track) and weather uncertainties. Alternatively, a pair of mobile ground systems operated by skilled personnel of Celestial Computing were also deployed and successfully repositioned to accommodate ground track shifts associated with Shuttle 24 hour waveoffs. Presently, both air and ground based systems used by HYTHIRM were configured with commercial CCD cameras to collect high spatial resolution imagery in the near-infrared wave-band. While this region of the IR spectrum is desirable for measurement of intensities associated with temperatures expected on the Orbiter lower surface $(\sim 1100-2000 \operatorname{deg} \mathrm{F})$ at hypersonic Mach numbers, it is not necessarily optimal for accurate measurement of tem- 
perature below 1100 def F. Other challenges persist in obtaining imagery to yield spatially resolved quality surface temperature data. The optical system in the Navy aircraft is based upon a gimbaled motion compensated mirror and operates near the diffraction limit based upon the telescope aperture. At a slant range of approximately $35 \mathrm{~nm}$, this system can theoretically yield a pixel resolution of less than a foot in the NIR bandpass. Under actual operating conditions, local atmospheric effects and blurring from vibrations and relative motion yield an effective resolution

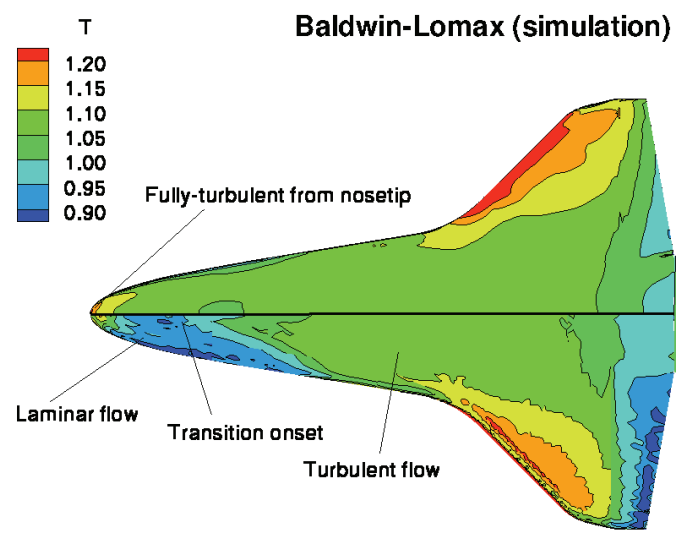

HYTHIRM (flight)

Fig. 4a. Comparison of Mach 8.4 Fully Turbulent CFD with STS-119 Thermal 3-D Mapping

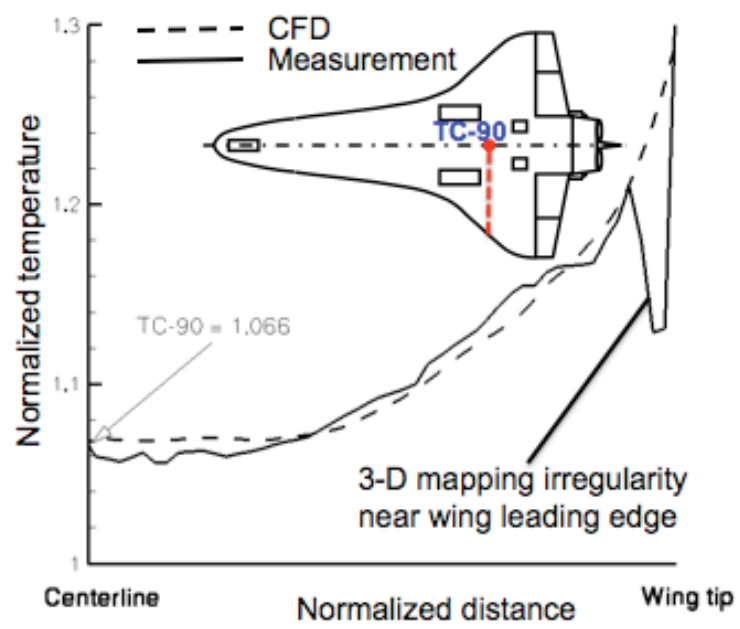

Fig. 4b. Comparison of Mach 8.4 Surface Temperature Distribution and Fully Turbulent CFD

limit (an optical system point spread function) of approximately 1.5 to $3 \mathrm{ft}$ at this slant range. The sensor on Cast Glance is generally configured for viewing from the starboard side of the aircraft. The desired viewing geometry (Shuttle lower surface) and starboard view configuration of the optical system can place constraints on the duration and quality of the imagery. On a few of the missions, the presence of obscuring clouds above the operating ceiling of the aircraft $(28,000 \mathrm{ft})$ has forced the crew to relocate from the desired observing position thus affecting the science objectives. Naturally, a ground system is more vulnerable to such atmospheric conditions with limited ability

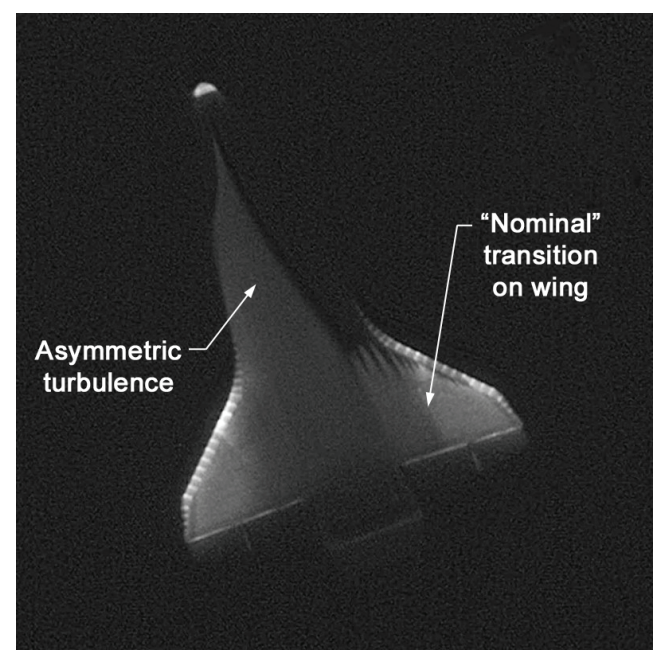

Fig. 5. Thermal Image of Endeavour During STS-134 Reentry as Viewed by the MARS Optical System. Mach 6.2, Slant Range $\sim 32.4 \mathrm{~nm}$ to relocate within hours of an observation. However, ground systems, free from the constraints of a window, offer the ability to deploy optical systems with much larger apertures and hence greater spatial resolution. Whether the imagery is obtained at altitude or at sea level, the challenges on the image processing side are similar and are largely associated with a high-angular rate observation and include management of frame-to-frame motions, motion-induced blurring with long exposure times, aircraft-induced vibrations, long atmospheric path lengths with ground-based optical systems, changing target orientations and ranges, daylight conditions, and sky backgrounds. Despite these factors, remarkable thermal imagery has been acquired for the Shuttle HYTHIRM missions because of diligent mission planning, execution and experienced asset personnel. An example of a 2-D thermal image that has been rigorously processed and mapped to a 3-D Orbiter surface is shown in Fig. 4a. Comparison of data from this image to an available thermocouple measurement at one point on the vehicle's centerline and to a CFD prediction is shown in Fig. 4b. A new process for providing 3-D thermography of the windward side of the Orbiter during hypersonic reentry has been applied to the STS-119, STS-125, STS-128, STS-132, and STS-133 observations. ${ }^{8}$ The most recent observation associated with a ground based optical system during En- 
deavour's historic last reentry (STS-134/June 2011) has provided the community with thermal imagery showing remarkable spatial resolution. With an estimated spatial resolution of approximately 4 inches per pixel at the point of closest approach, the imagery obtained by the Mobile Aerospace Reconnaissance System (MARS) operated by Celestial Computing was sufficient to reveal thermal gradients associated with the 22 individual wing leading edge carbon-carbon panels. In what is believed to be an historic first, the evolution of hypersonic laminar to turbulent flow transition has been captured globally during Endeavour's descent and return to KSC. With the optical system positioned in a location complementary to the Orbiter's glide path, thermal patterns on the windward surface resulting from this flow transition process at approximately Mach 6.2 are shown in Fig 5. Regions of elevated temperature are shown in lighter gray. Clearly evident in this intensity measurement is the large area of asymmetric BLT on the starboard (lower) wing that is remarkably similar to that observed on Discovery (STS-119/March 2009) by Cast Glance (Fig. 1). Thermal detail on the port side (upper wing) show what appears to be the leading edge of the BLT front induced (presumably) from the distributed tile-to-tile step/gap roughness.

Leveraging from the mission tools developed by the NESC and the successful flight observations sponsored by the Shuttle program, the NASA Commercial Crew \& Cargo Program Office (C3PO) requested HYTHIRM conduct an observation in support of the maiden flight of the Dragon capsule (2010). The charter of C3PO is to extend human presence in space by enabling an expanding and robust U.S. com-

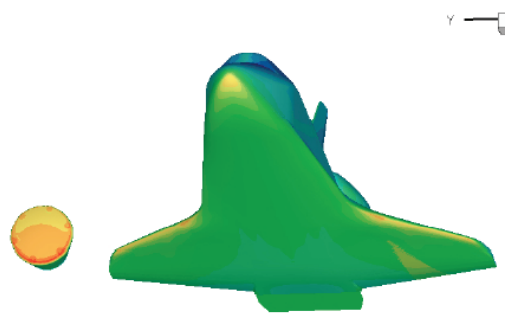

Fig. 6. Relative Size and Temperature Differences Between Shuttle and an Apollo-Like Capsule mercial space transportation industry. As part of this charter, it is responsible for managing NASA's Commercial Orbital Transportation Services (COTS). Under COTS, NASA seeks to assist industry in developing and demonstrating its own cargo space transportation capabilities. Industry leads and directs its own efforts with NASA providing technical assistance. Initial $\mathrm{C} 3 \mathrm{PO}$ interests in imagery were focused towards general vehicle health and performance monitoring during ascent/reentry and the collection of forensic information in the event of an off-nominal flight during the initial COTS demonstration missions. Leading up to the first flight of the SpaceX Dragon capsule, these initial objectives evolved towards collection of the data in a manner that would permit calibrated radiometric infrared imagery during reentry to infer the heatshield temperature and to correlate with on-board instrumentation. In an ancillary risk reduction task, one of the airborne assets deployed for this observation was used to record telemetry sent to the ground from the capsule during reentry. Had search and recovery efforts been required, the aircraft was equipped with surface radar to locate and direct the SpaceX recovery vessels. With a nominal entry, the aircraft provided aerial photo documentation of the capsule recovery process. This multifunctional capability makes aerial data collection attractive. Working closely with SpaceX, the mission was a remarkable success and highlights the general philosophy of mutual trust while maintaining verification as part of NASA's due diligence. For comparative purposes, the relative size and expected temperature difference between the Shuttle and a generic capsule is shown in Fig. 6. Based upon the expected surface temperatures on the Dragon capsule heatshield, the standard dynamic range and sensitivity of the NIR detector on Cast Glance was determined to be acceptable. In Figure 7, a sequence of intensity images (Mach 21-17) was captured as the Dragon capsule reentered the earth's atmosphere over the Pacific Ocean towards a successful recovery. In this sequence, the view of the heatshield becomes foreshortened as the capsule approaches the aircraft. The slant range from the capsule to the aircraft at the point of closest approach was nearly identical to a Shuttle observation and hence the expected resolution subtended by each pixel would be similar $(\sim 1.5 \mathrm{ft})$. As the pre-flight modeling tools had indicated, the overall dimensions of the capsule placed a reduced number of pixels on the Dragon heatshield (relative to Shuttle). Most notable in the time sequence of intensity images in

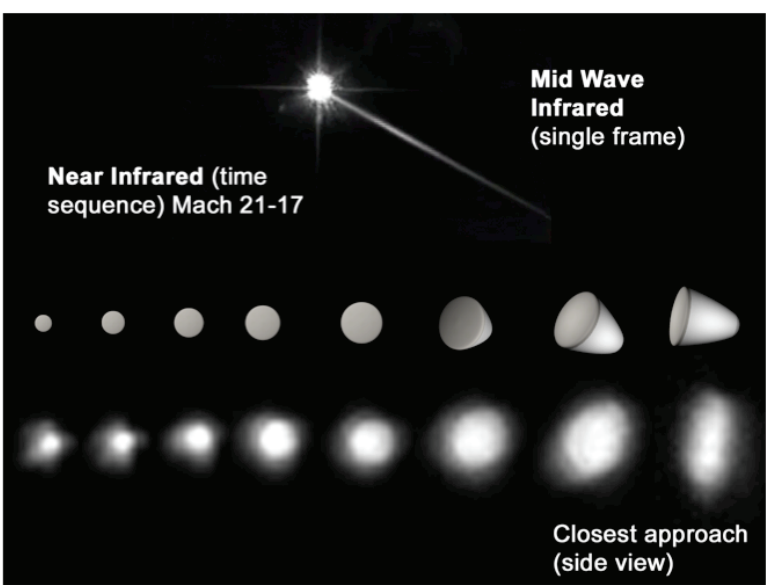

Fig. 7. Infrared Intensity Images Obtained on the SpaceX Dragon Capsule During Reentry on Dec. 8, 2010. Fig. 7 is the (apparent) absence of the Dragon capsule backshell. As indicated by pre-flight radiance modeling, the lower temperatures in this region were insufficient to 
permit the backshell to be distinguished from the sky background in the NIR wave-band. At the time of this publication, post flight analysis to convert the heatshield intensity measurements had just been initiated.

HYTHIRM support to the Maximum Launch Abort System (MLAS) flight test highlighted the utility of visual imagery. MLAS was a proposed alternative to the more traditional tower escape system used during launch of the Apollo. An NESC sponsored "pad abort" flight test of the MLAS was performed at NASA's Wallops Flight Facility in $2009^{32}$. Baseline imaging requirements were satisfied with existing range assets. The Mobile aerospace reconnaissance system (MARS) ground optical system operated by Celestial Computing was used by HYTHIRM to provide the NESC with long-range high definition video and infrared imagery to complement and extend the capabilities provided by the range. Long-range imaging was desired as the vehicle trajectory lofted the test article approximately 3 miles off the coast of the Wallops test range. The imagery requirements for MARS were to document the nominal (or off-nominal) sequence of events during the flight-test using both wide and narrow field of view optics. Multiple long-range cameras on a single mount were selected to allow simultaneous imaging of the flight, with each instrument capturing a unique image scale, wavelength range, intensity range, or temporal sampling. The emphasis of the observations was focused on high-resolution still images and high-definition video documenting the flight of the Command Module (CM) upon release from the booster. Site selection was chosen to

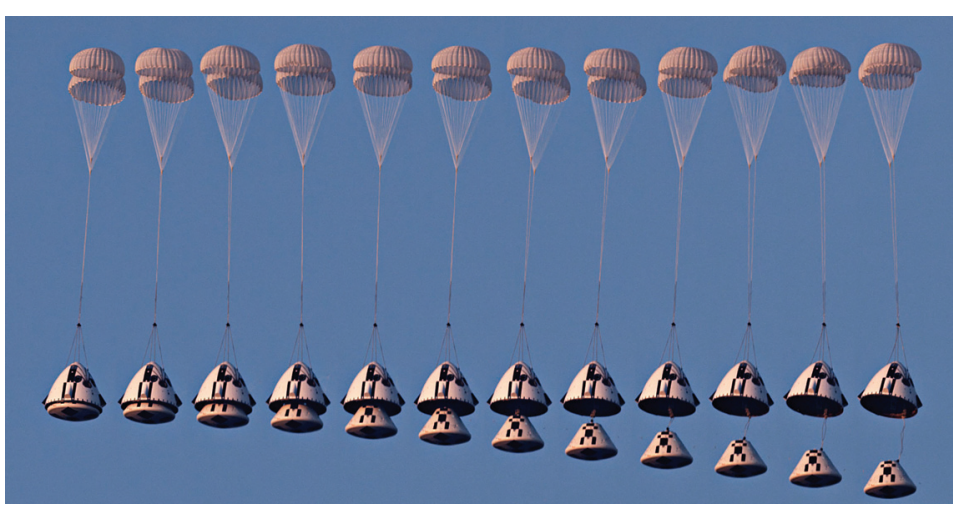

Fig. 8. High Resolution Imagery from the MARS Ground Optical System Complemented Range Assets for the NESC Launch Abort Test at the Wallops Flight Facility. meet range safety requirements and also provide a location close to the launch site, with minimum, or no, line-of-site restrictions. As is done with airborne observations, HYTHIRM virtual simulation tools provided view perspectives, sun angle and expected resolution. Critical events associated with the landing chute parachute experiment were captured and included capsule drogue chute deployment, CM fairing separation, $\mathrm{CM}$ drogue deploy, $\mathrm{CM}$ main parachute deploy, and water impacts of the $\mathrm{CM}$ and fairing. With the capsule 3 miles distant, a spatial resolution of less than 0.25-in per pixel was achieved revealing remarkable details of shroud separation and parachute performance including final water impact. Images were used by NESC analysts to determine predicted versus actual $\mathrm{CM} / \mathrm{Fairing}$ separation timelines and relative positions. A selected time sequence of visual images the CM separation from the shroud is shown in Fig. 8. Using a reference method, capsule deceleration was inferred from these images along with subsequent water impact angle (not shown). As an exploratory exercise, short-wave infrared (SWIR) imagery was also acquired by MARS despite the fact that thermal issues were not expected during this flight. The thermal imagery (unexpectedly) yielded better contrast of with the particular parachute fabric material that was flown. This aspect suggests the possible use of thermal imagery to more optimally detect flaws or rips. While successful, this observation pointed to the criticality of detailed mission planning. Autonomous image recognition and tracking algorithms were unintentionally aborted as the larger than anticipated plume from four MK70 solid rocket motors at launch initiation briefly obscured the image of the capsule. Loss of data occurred during the boost phase as well as some of the staging events. Manual tracking methods were used to reacquire the target and all primary objects were met.

NASA's Ames Research Center and the SETI Institute have collaborated on the airborne observation of several spacecraft reentries. Unlike HYTHIRM's focus on spatially resolved thermal imaging, the Ames-SETI efforts primarily focused on emission spectroscopy of comparatively small-sized entry vehicles returning extraterrestrial samples from exploration missions. The primary objective of these airborne observations was to obtain timeresolved measurements of absolute spectral irradiance from the entry vehicle and its trailing wake. The data are interpreted to reveal quantities of importance to atmospheric entry aerothermodynamics: apparent temperatures, shock radiation spectra, ablation species spectra (if present), and their temporal evolution during entry. The first of these collaborations was for NASA's Genesis reentry in $2004^{33,34}$ followed by NASA's Stardust in $2006^{35-47}$ and JAXA's Hayabusa in 2010. ${ }^{48,49}$ The Genesis airborne reentry observation campaign used the (now retired) US Air Force Flying Infrared Signature Technology Aircraft (FISTA). The Stardust and Hayabusa observation campaigns used NASA's DC-8 airborne laboratory. The Genesis sample return capsule (SRC) reentry was the first vehicle since the Apollo era to reenter Earth's atmosphere at superorbital velocities. All three SRC's utilized ablative heat 
shield materials to absorb, transform, and reject the high heat fluxes encountered at superorbital entry velocities. The high entry velocities also induce substantial shock layer radiation - and non-negligible radiatve heating - compared to reentry from low earth orbit. Both the Genesis and Stardust SRC reentries landed in the Utah Test and Training Range (UTTR) in northern Utah for sample recovery. The Hayabusa SRC reentry landed in Australia's Woomera Test Range in South Australia.

The approach taken by the Ames-SETI group was to use multiple instrument platforms with complementary and redundant capabilities. The spectral coverage ranged from the near ultraviolet to the short wave infrared to target shock-heated air species (atomic $\mathrm{N}$ and $\mathrm{O}, \mathrm{N} 2, \mathrm{~N} 2+$ ) and species resulting from ablation of the heat shield $(\mathrm{C}, \mathrm{H}$, $\mathrm{CN}$, trace atoms and ions). Many of the instruments were slitless spectrographs that utilized transmission gratings. A camera with a transmission grating can simultaneously record an image and dispersed spectra of the light radiated by the capsule, shock-heated gas, and trailing wake. The spectral resolution was sufficient to resolve atomic line and molecular band emission from air species and heat shield ablation species and their reaction products. The

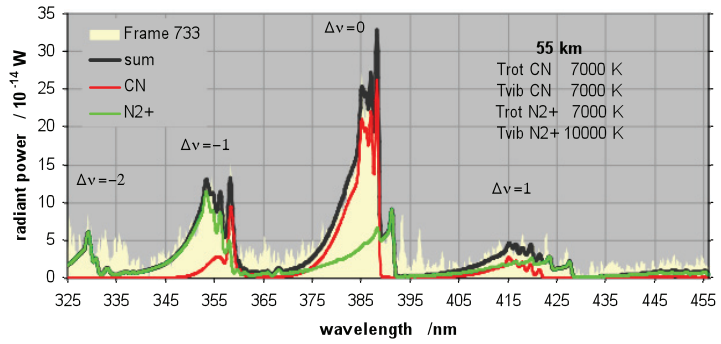

Fig. 9. Measured and Simulated Emission of $\mathrm{CN}$ Violet and $\mathrm{N2}^{+}$first neg. at an Altitude of $\mathbf{3 4 . 2}$ miles. (Ref. 47) technique, often used in astronomy, is appropriate for singular or sparse point sources within the camera's field of view. Other instruments employed fiber-coupled slit spectrographs or cameras with band pass filters to realize spectral resolution. High-resolution color video cameras were also part of the instrumentation suite used on these observation missions. The use of multiple instruments with overlapping spectral ranges and other performance characteristics was intended to mitigate potential data loss due to instrument failure and target acquisition/tracking failure. Due to the small size of the SRC and the distance between the SRC and the observing aircraft, the imaging instruments on board the aircraft were unable to distinguish spatial distributions of the emitted SRC surface and surrounding gas radiation; the SRC appeared to the instruments as a point source of light, and the apparent magnitude and spectra of the observed emission signatures were weighted by the relative magnitudes of the gas and surface radiation and angular integration of their spatial distributions. The unresolved thermal (blackbody) emission from the heat shield surface was used to infer an apparent surface temperature as a function of altitude. Post-flight analysis using reconstructed trajectories and aircraft-target slant range distances enables comparison of the measured spectra to combined CFD/radiation transport/thermal response simulations of the capsule reentry. ${ }^{40}$

An example of spectral data and subsequent analysis from the Stardust SRC reentry is shown in Fig. $9 .{ }^{47}$ The spectrum in the near ultraviolet was acquired with a fiber-coupled slit spectrograph. This frame from the full timeresolved data set was recorded just after peak heating at an altitude and velocity of 34.2 miles and $31.5 \mathrm{ft} / \mathrm{s}$, respectively. The instrument was designed to capture emission from $\mathrm{N} 2{ }^{+}$and $\mathrm{CN}$ at high resolution. Also shown in Fig. 9

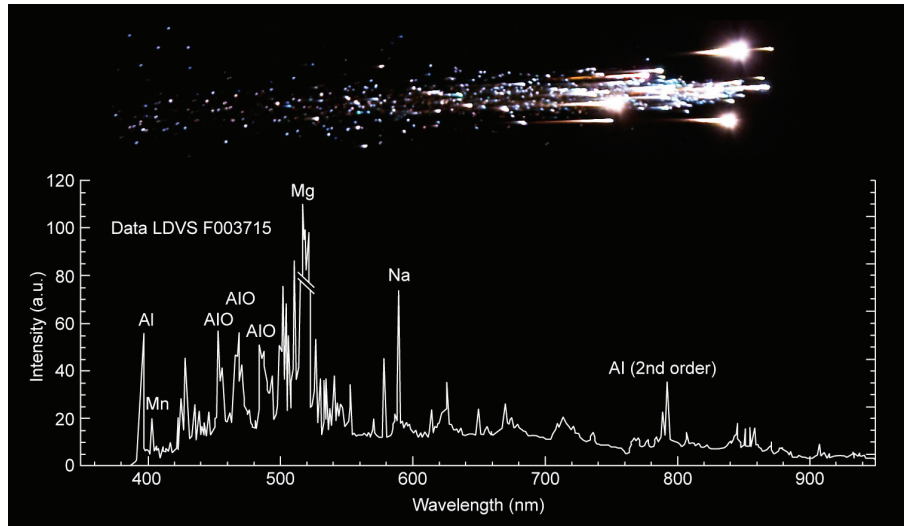

Fig. 10. Uncalibrated Fragment Spectrum from the Hayabusa Spacecraft Bus Reentry Disintegration. Emission Lines and Bands of Several Chemical Species are Identified. are curve fits of rotational and vibrational band simulations of the $\mathrm{N} 2+$ first negative and $\mathrm{CN}$ violet systems at assumed rotational and vibrational temperatures. While these apparent temperatures have limited utility due to the angular integration over the spatial distribution of the vehicle, the curve fits enable discrimination of the two superposed band systems for analysis of their spectrally integrated magnitudes. When correlated to the reconstructed trajectory, these altituderesolved values indicate the relative variations of shock radiation and ablation processes during reentry. Radiation transport analyses of high resolution NIR spectra of atomic $\mathrm{N}$ and $\mathrm{O}$ from the shock layer have also been performed ${ }^{38}$ and further demonstrate the utility of spectral 
measurements from the Stardust SRC reentry.

A similar but distinctly different observation, also led by NASA Ames and SETI, used the NASA DC-8 and a privately owned Gulfstream V to observe the destructive reentry of the European Space Agency's (ESA) Jules Verne ATV-1 (Automated Transfer Vehicle). ${ }^{50}$ The ATV-1 was the first of a series unmanned cargo vehicles to ferry supplies to the International Space Station. This and future ATVs will not provide down mass capability once it has completed its mission, an ATV will be undocked and de-orbited for controlled reentry and disposal in an uninhabited region of the south Pacific ocean. Observation of the ATV-1 reentry was requested by ESA to obtain explosive event histories, break-up altitudes, and fragment trajectories for evaluation of destructive reentry models. Aircraft were essential for this observation due to the remote south Pacific location. The ATV-1 reentry in September 2008 provided a unique opportunity to obtain quantitative visual and spectral imagery associated with the complex break-up and disintegration. Since fragment trajectory reconstruction was a primary objective of the observation, two aircraft were used to enable triangulated astrometry from images acquired simultaneously from two widely separated vantage points. The ATV-1 observation presented new challenges for flight path planning for the two aircraft. ${ }^{50}$ Realizing optimum viewing conditions also required coordination with ESA's ATV control center. Measurements associated with the initial breakup and subsequent fragmentation yielded a wealth of spectral data that are currently being analyzed to identify a fragment trajectories, dynamics, and chemical constituents.

The Hayabusa mission's return to Earth resulted in a predicted but unintended combination of a successful sample capsule reentry and destructive reentry of the main spacecraft bus. The Hayabusa mission suffered several component failures and system malfunctions that left the spacecraft without chemical propulsion and with only partial use of its ion thrusters. JAXA was able to recover enough functionality to navigate the spacecraft for Earth return to the targeted region in South Australia. However, the lack of chemical propulsion prevented the planned spacecraft diversion maneuver after release of the SRC prior to reentry. The spacecraft followed the SRC into the atmosphere along the same trajectory. While in close proximity, the SRC and spacecraft were well separated, and all airborne imaging instruments simultaneously captured the SRC reentry and spacecraft disintegration. As with the ATV-1 observation, the high-resolution slitless spectroscopy instruments used for the Hayabusa observation were able to spatially discriminate individual bus fragments for analysis. An example of a preliminary, uncalibrated spectra of one bus fragment is shown in Fig. 10, where several expected chemical species have been identified. These and similar data will aid understanding of the complex thermal, structural, and aerodynamic processes that influence the destructive reentry of spacecraft and orbiting launch debris.

This section concludes with an example of quantitative imagery as applied to a launch configuration. During the inaugural launch of the Atlas 5 launch vehicle (2002) observations were made using a dual-band infrared focal plane array $^{24}$. The dual-band detectors are able to sense light in both the MWIR and LWIR wave-band such that the two resulting single-band images are simultaneously pixel registered. Collected in this manner, it is possible to infer surface temperature to a greater degree of accuracy. In this particular application, target recognition was the motivating force behind the observation. The MWIR and LWIR signatures of rocket vehicles and their plumes in boost phase are of great importance to the Missile Defense Agency (MDA) in terms of evaluation of ballistic missile threats. It is well known that rocket plumes present a large MWIR signal that may be detected and tracked at large distances (hundreds of miles). The dual band detector in this observation was used in conjunction with a telescope on a computer-controlled tracking mount at the Innovative Sensor Technology Evaluation Facility (ISTEF) at the Kennedy Space Center. The launch vehicle was observed from about 30 s after launch $(\sim 10$ miles distant $)$ until approximately 4 minutes after launch $(\sim 200$ miles distant). The calibrated imagery was unsaturated in both bands allowing quantitative measurements of the radiance of the plume in both the infrared bands. In Ref. 24, MWIR and LWIR plume radiance signatures measured in flight were compared to simulated signatures. The model underestimated the maximum radiance of the plume by a factor of 2 in the MWIR and by a factor 5/3 in the LWIR. In addition, the model did not predict details of the structure within the measured plume as shown in Fig. 11. The hardbody of the rocket was seen in the LWIR imagery and was used to determine surface temperature gradients during ascent and was of sufficient 
resolution to reveal the presence of the cryogenic liquid oxygen tank below the first stage. The use of a ground system constrained the ability to maintain a side aspect view. As the Atlas rocket transitioned from its vertical climb from the launch pad to a due east course over the Atlantic the viewing aspect of the plume changed significantly going from a mostly side aspect to an end-on aspect. In addition, it was noted that during some periods of ascent, the vehicle was obscured by clouds and hence, no reliable signature data was collected.

\section{Future Imaging Applications}

Over the last decade, optical methods for extracting surface and flow-field measurements have begun to complement (or replace) the traditional discrete sensor measurement approach when testing in ground-based wind tunnels. The global nature of the information and the reduced complexity and expense of the instrumentation (installation and recording) are large driving forces behind this trend. The opportunity exists for a similar paradigm shift in terms of how data is measured in flight is obtained. Despite the ever-present uncertainties in budgets and technology investments in aerospace systems, the near term horizon suggests an abundance of flight tests and operational activity as illustrated in Fig. 12. Safe, economical and environmentally responsible access to space is a major technological challenge for all nations due to the dependence of the global economy on assured and secure access to space-based services. To this end, the U.S. government and the commercial sector are embarking on a series of ambitious new programs that will eventually culminate with testing and demonstrations in flight. It is suggested that the quantitative imaging applications offered in the previous section may offer unique (or complementary) measurement alternatives to assure vehicle health and maximize the return on investment in terms of developmental flight test data for future vehicle design. Some of the programs identified in this section are actively flying hardware and could potentially take advantage of existing imaging infrastructure to address requirements grounded in a technical basis. Other programs are in the developmental or conceptual stages and, if warranted, top-level imagery requirements could be properly integrated into the planning process. The most effective use of quantitative imagery requires an Agency-sponsored system dedicated to collecting observational data with which science and engineering requirements can be satisfied. Collectively, the programs and projects identified herein are not intended to be allinclusive, but rather are highlighted to serve as a catalyst for further dialog regarding the balance of program objectives and the actual needs of the engineering, science and surveillance communities.

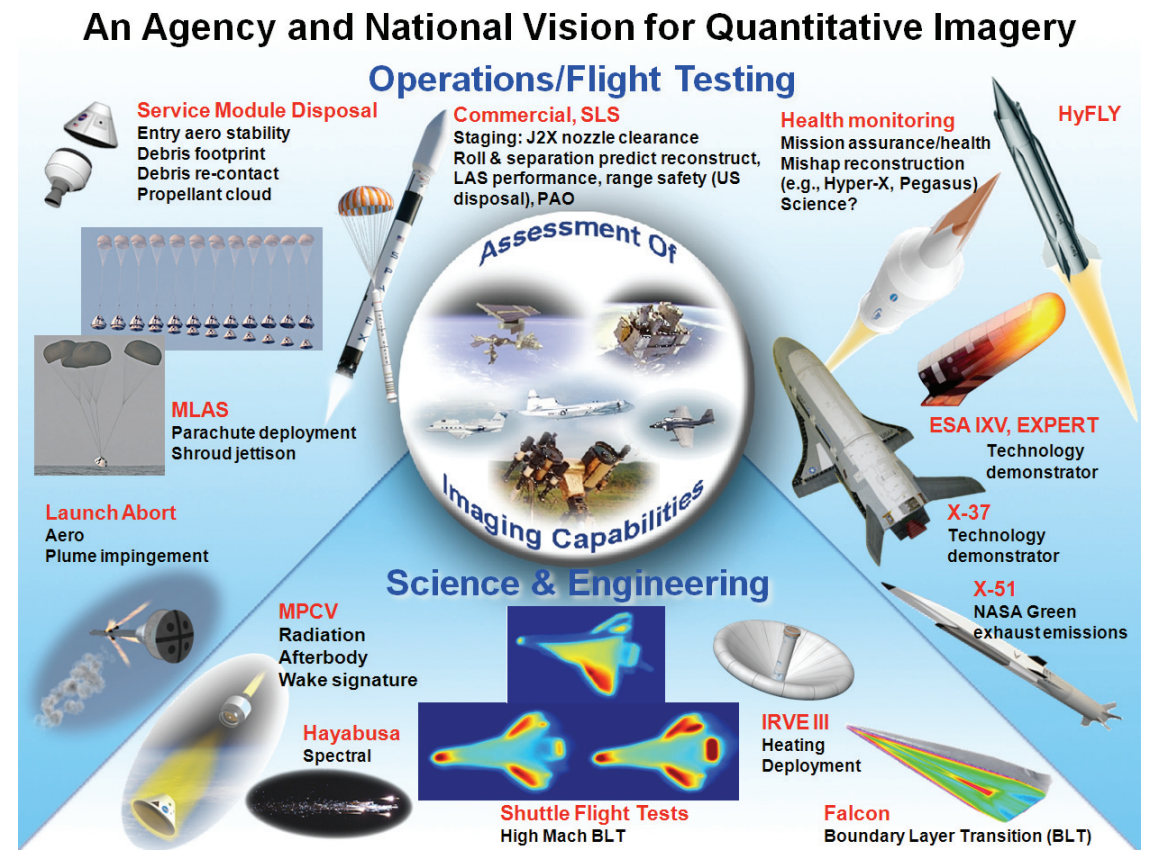

Fig. 12. Programs Potentially Benefiting From a Quantitative Imaging Capability

One active area of flight test is in response to a desire for a prompt national global response (strike) capability. The various U.S. military services have proposed many conceptual vehicles; many of which have evolved past the conceptual stage towards flight hardware; the most notable being the DARPA/AF HTV-2. Despite the flight anom- 
aly on the maiden flight of HTV-2, the program has shown remarkable resilience and is postured for a second flight in late 2011. If successful, this could lead to a series of follow-on flights incrementally expanding the performance envelope. Others concepts include Army Advanced Hypersonic Weapons (AHW) program ${ }^{\mathbf{5 1}}$ and the DARPA/U.S. Office of Naval Research effort to evaluate a rocket-boosted ramjet-scramjet propulsion system, HyFLY ${ }^{\mathbf{5 2}}$. At the time of this publication, the second X-37 technology test-bed vehicle built by Boeing is in orbit on a mission of a classified nature and duration. The highly successful first flight, successful autonomous return (no crew) and the desire to expand the operational envelope, the $\mathrm{X}-37^{\mathbf{5 3}}$ would naturally be a strong candidate to benefit from the emerging thermal imaging capability demonstrated by HYTHIRM. Hypersonic air-breather development continues with the AFRL/DARPA X-51 Scramjet Engine Demonstrator Waverider Program ${ }^{\mathbf{5 4}}$. Commercial entities such as Boeing, SpaceX, Orbital Sciences, Sierra Nevada, Blue Origin, and Virgin Galactic are all in various stages of demonstrating launch and orbital operations capabilities to deliver crew and/or cargo to the ISS (or suborbital services for science and tourism). Naturally, the NASA Commercial Crew Development program (CCDev) will be active catalyst to stimulate this commercial crew transportation capability within the private sector. It is likely that the development of a new space launch system (SLS) within NASA will result on additional flight-testing similar to the ARES 1-X and Pad Abort (under Constellation) and MLAS (under the NESC). Draft SLS requirements for launch and fly away include assessment of debris survival from post mission disposal during atmospheric reentry. Very specific restrictions on the proximity of the reentry debris impact footprint area relative to landmasses. Verification shall be considered successful when the analysis results show the impact footprint does not violate the specified boundaries. X-band radar and imagery are essential to this type of verification. On the international front, the pace of flight test activity continues to pick up as well. The European Space Agency's Future Launcher Preparatory Program (FLPP) is embarking on several flight test programs (i.e., IXV ${ }^{55}$, EXPERT ${ }^{56}$ ) aimed at obtaining high quality aerothermodynamic flight data. The Australians (in partnership with NASA and the U.S. Air Force) continue to advance hypersonic air-breathing technologies with the HIFIRE ${ }^{\mathbf{5}}$ sounding rocket program. The German Aerospace Center (DLR) will continue to expand the operating envelope of an advanced hypersonic demonstrator $\left(\right.$ SHEFEX) ${ }^{58}$. The test vehicle for the second flight (targeted for 2011), is intended to evaluate multiple different thermal protection systems concepts.

Exploratory dialog with a few programs have been started to determine their specific requirements and if verification can be achieved or enhanced with imagery. Current NASA plans call for a 2013 flight demonstration of the Multi Purpose Crew Module (MPCM) to validate technologies for accessing space beyond low earth orbit. Similar to the interests of the Commercial Crew \& Cargo Office, imagery is desired to monitor the capsule reentry in the event of any mission anomaly. The technical community has expressed a desire for global heatshield surface temperatures derived from calibrated radiometric imagery to complement limited surface thermocouple measurements. Early assessments indicate spectrally and temporally resolved shock layer radiation measurements from a remote observation are not feasible. These assessments show that while radiative heating from the shock layer gases is not

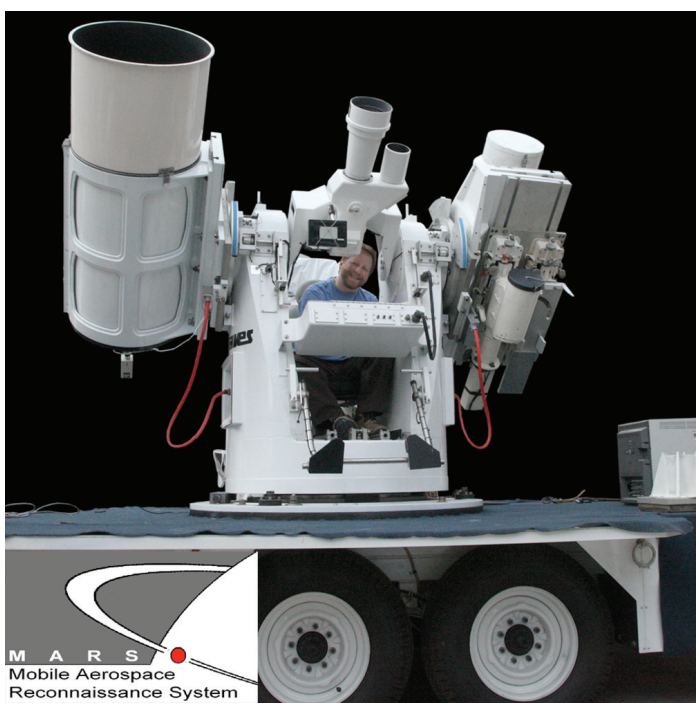

Fig.13. Evolution of the MARS Optical System Towards a Next Generation Imaging Capability. negligible at the desired entry speed, it will be too weak (less than $0.05 \%$ of the total) to discriminate against the signatures emanating from the thermally bright aeroshell surface (as seen by a remote observer). Such spectral measurements, however, could provide an indirect metric of the Avcoat TPS performance by the time-tagged detection (or absence) of excited species and ablation products in the near and far wake. The ability to detect these ablation species and wake radiation spectra will require further analysis with input from the Orion TPS and aerothermal communities.

Over the next two years, the NASA CEV Parachute Assembly System (CPAS) Project will conduct testing at the Yuma test range to assess parachute deployment characteristics. The project is presently evaluating a proposal to augment range assets with a state-of-the-art hand held gyrostabilized high definition system for use on a UH-1 helicopter that will be providing air-to-air coverage. Under such demanding high vibration environments, a stabilized system is 
required to provide quality visual air-to-air imagery of the deployment, disreefing, inflation, and overall performance of the parachute test article(s). Long-term test plans include high altitude balloon drops. The locations being considered for these tests will limit (or possibly exclude) the use of traditional range optical systems. Exploratory dialog is being pursued to field a mobile optical tracker (Fig. 13) equipped with large aperture optics that would provide the necessary spatial resolution. This new next generation system operated by the Mobile Aerial Reconnaissance (MARS)/Celestial Computing represents an advancement in capabilities of the system utilized by the NESC in visual/thermal observations of MLAS and the Shuttle (STS-134).

To enable a truly cross cutting technology for atmospheric entry associated with a variety of destinations with atmospheres (i.e., Earth, Mars, Venus, Titan and the gas giants), the NASA Hypersonic Inflatable Aerodynamic Decelerator (HIADS) project seeks to flight demonstrate an inflatable TPS aeroshell concept. An inflatable design has the potential for increased packaging flexibility and reduced mass. Ground based testing efforts alone are not sufficient to demonstrate the technology in relevant environments. The project plans to continue flight tests at proposed scales and mass requirements. The project is currently assessing the potential for collecting thermal and imagery in support of these flight tests to be performed from the NASA Wallops Flight Facility. Current costs for supporting small-scale demonstration projects such as HIADS challenge the current HYTHIRM business structure. Development of an affordable imagery system will be crucial in terms of support to projects of the nature.

\section{A Vision Forward}

Despite the interest expressed by the engineering and flight operations communities in existing imaging capabilities, the application towards the development of new aeronautical or aerospace systems will challenge current remote observation capability in terms of metrics derived from spatial/spectral resolution and temperature sensitivity requirements. Furthermore, while highly reliable, the current methods employed by HYTHIRM to acquire in-flight imagery rely on an array of inherently expensive assets that include manned airborne and ground based optical systems. The first step towards an affordable Agency level imagery-based measurement capability to meet present and future needs is to undertake an independent assessment study to characterize the market forces and quantify the cost benefits that would drive the development of a cross cutting imagery system (i.e., sensor, platform and data analysis infrastructure) to serve the broad needs of the NASA mission directorates. Naturally, querying the scientists, engineers and operations personnel within the flight test community to understand top level requirements and define a comprehensive set of objectives identifying the functional role of quantitative imagery will be an important element of an assessment. This paper serves a basis from which to initiate that dialog with the technical community. To some extent, this dialog interaction is already occurring within NASA's Science Mission Directorate (SMD). The leadership within SMD has recognized that unmanned aircraft systems (UAS) have the potential to transform the way airborne science platforms contribute

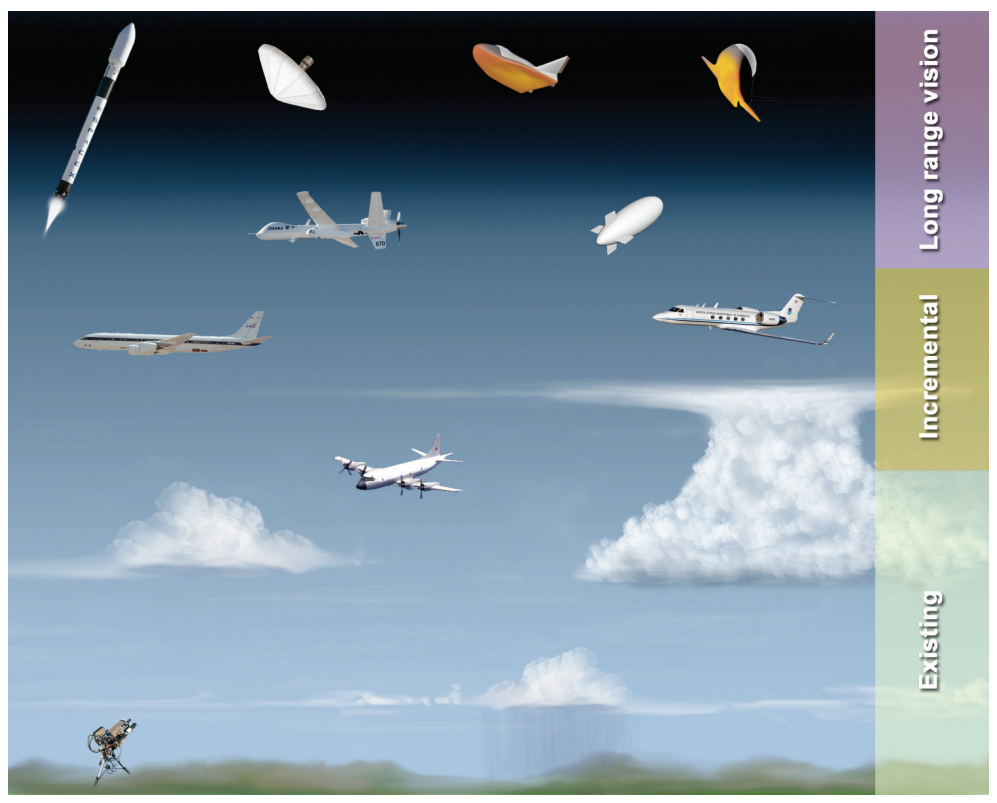

Fig.14. Evolutionary Autonomous and Robotic Imaging System to Support the Needs of the Flight Test Community. to earth science related investigations and environmental monitoring. The UAS application of SMD is focused towards the solicitation and evaluation of proposals regarding the use of autonomous aerial systems and advanced remote sensors for conducting earth science and atmospheric research. Expanding that innovative thinking to include aeronautical research and the acquisition of vehicle performance data associated with future aerospace systems could enable a paradigm shift towards a reli- 
able, flexible, affordable, less evasive process of maximizing the return on investment of NASA flight testing by complementing, enhancing or in limited cases, replacing the traditional in-situ DFI measurement approach.

As conceptually shown in Fig. 14, a truly affordable, next generation system might entail a smaller more versatile system; a "smart sensor payload" with a UAS (or high altitude airship) optimally designed around it. In this long-range vision, sensor and platform are integrally connected. Sensor inputs would permit completely autonomous operations (i.e., no remote pilot) even in GPS-denied environments. Using intelligent flight controls and a payload-directed flight, this next generation imagery system would ultimately permit autonomous long range target acquisition, tracking, image stabilization and enhancement, real-time sensor re-configuration/wave-band selection and aircraft attitude/orientation to optimize the data collect thus significantly increasing mission flexibility while reducing operational costs. Because UAS are capable of long-duration loitering, they are ideal for observations where there is uncertainty in mission timelines (i.e., launch or reentry delays). Because they are unmanned, UAS are also ideal for conducting operations in remote, dangerous or restricted airspace where there is risk to pilot and aircraft. As noted earlier, a high altitude capability places sensors well above the detrimental effects of the atmosphere. To make optimal use of the platform capabilities to fulfill future science and engineering objectives and most importantly, facilitate and provide direction to this vision, a system trade study becomes imperative to identify gaps between the existing optical and detector technology, new sensor concepts and platform command and control architecture.

Within the last several years, the MDA has been experimenting with demonstration of a tracking capability using unmanned drones outfitted with the IR sensors to detect a ballistic missile during boost at distances up to 625 miles. At these extreme distances, an infrared sensor has limited ability to discriminate but it has greater potential for tracking. As one might imagine, imagery system requirements to detect a target at ranges up to 625 miles are quite different than the spatially resolved thermal measurements pursued by HYTHIRM. For their particular mission objective, the MDA has concluded that a specific fleet of UAS would be cost prohibitive, so their focus is on the design of a pod, which could be flown on any remotely piloted vehicle rather than designing the imaging capability into a specific platform ${ }^{59}$. Despite the apparent differences in mission objectives between the MDA and the goals of HYTHIRM, it is recognized that many of the platform and tracking challenges are very similar, suggesting potential leveraging and partnership opportunities for development of hardware (sensor/optics), software (command and control, robotic, image processing) and platform (UAS, airship, semi autonomous, fully autonomous). In the reality of today's national fiscal constraints, identification and pursuit of such partnerships with cross cutting technology applications are desirable. Based upon current strategic thinking, NASA intends to facilitate an even more pervasive use of UAS in its future. Current UAS systems are part of a larger topic area of robotics and autonomous systems. Such systems are primarily automated, able to respond to a predicted set of conditions and have critical human interaction and control. The goal of robotic and autonomously operated systems is to develop technologies and capabilities that will lead to fully autonomous systems that are able to learn and adapt to changes in their environment that were not predicted to accomplish the mission goals with minimal or no human involvement. The time horizon for a UAS based imaging system is imminent as there are significant ongoing national and international efforts to integrate UAS operations into sovereign airspace. It is now an opportune time to work UAS payload integration challenges. Specific technology areas of interest to NASA include perception, cognition, mobility, sense and avoid, manipulation, human-systems interfaces, autonomous rendezvous and docking, and multi-robotic systems that autonomously cooperate to achieve mission objectives. The HYTHIRM vision supports a scenario where autonomous systems are used as a reliable, flexible and affordable system capable of responding to the needs of the Agency mission directorates and the engineering/science communities. To enable such a capability, the system must be viewed as a required, rather than an optional, investment. Regardless of the platform/sensor choice, it is the author's belief that a fractured, compartmentalized approach towards a quantitative imagery capability within the Agency will likely not be successful and will most certainly not be cost effective.

\section{Summary and Recommendations}

Over the last decade, optical methods for extracting surface and flow-field measurements have begun to complement (or replace) the traditional discrete sensor measurement approach when testing in ground-based wind tunnels. The global nature of the information and the reduced complexity and expense of the instrumentation (installation and recording) are large driving forces behind this trend. The opportunity exists for a similar paradigm shift in terms of how data is measured in flight is obtained. Despite the ever present uncertainties in budgets and technology investments in aerospace systems, the near term horizon suggests an abundance of flight test and operational activity. Safe, economical and environmentally responsible access to space is a major technological challenge for all nations due to the dependence of the global economy on assured and secure access to space-based services. 
To this end, the U.S. government and the commercial sector are embarking on a series of ambitious new programs that will eventually culminate with testing and demonstrations in flight. The quantitative imaging applications offered in this paper offer unique (or complementary) measurement alternatives to assure vehicle health and maximize the return on investment in terms of these developmental flight tests for future vehicle designs. Flight measurements of any new system, in particular a hypersonic vehicle, is imperative to engineers as it provides the first set of insights from which to truly evaluate design assumptions, assess performance margins and ultimately better characterize the nature of the weaknesses of database design tools. Based upon the initial success of Hypersonic Thermodynamic Infrared Measurements (HYTHIRM) team in capturing calibrated thermal imagery of the Orbiter during reentry (and later during a test flight associated with NASA's Commercial Orbital Transportation Services), the traditional role of imagery as largely a public relations tool has been challenged.

As NASA embarks on its new space launch system, an opportunity exists at the Agency level to implement a top down requirements approach to designing and developing an imagery system and its supporting infrastructure that provides sufficient flexibility to incorporate changing technology to address the future needs and objectives of the flight test community. Recent observation campaigns were used to highlight potential future applications and stimulate an honest dialog of program and technical requirements that could be satisfied with imagery. Despite the interest expressed by the engineering and flight operations communities in utilizing the existing imaging capabilities, the application towards the development of new aeronautical or aerospace systems will challenge current remote observation capability in terms of metrics derived from spatial/spectral resolution and temperature sensitivity requirements. To meet the future needs of the science and engineering community in development of critical enabling technologies necessary for (but not limited to) hypersonic aerothermodynamics, high-temperature materials for thermal protection, flight dynamics and range safety including launch and reentry, a next generation imaging system is required. Analogous to Agency investments (DC-8, SOFIA etc.) used by NASA to support earth science, atmospheric science, and astronomy - HYTHIRM advocates for an Agency level vision supporting the application of an imaging system consisting of advanced visual, thermal and spectral sensing technology to support aeronautics and aerospace research including flight test. To accomplish this, a commitment must be established through requirements definition at the program and project levels within the Agency mission directorates. The technology proposed herein can be tied directly to NASA's Space Technology Grand Challenges, specifically to improve spacecraft safety and protect astronaut health; and achieve fast and economical space transportation. The technology also supports at least three of the NASA Langley revolutionary technical challenges, namely the characterization of entry/traversal through planetary atmospheres; earth to orbit spaceliner; and affordable exploration. Finally, the proposed technology could contribute to closing several DoD, Missile Defense Agency and Homeland Security technology shortfalls.

One path to a truly affordable, next generation system might entail a smaller more versatile robotic system; where sensor inputs would permit completely autonomous operations (i.e., no remote pilot). Using intelligent flight controls and a payload directed flight, a high-altitude imaging asset could significantly increase mission flexibility while reducing operational costs.

To rigorously determine the technical and economic viability of a robotic autonomously controlled imagery system, the following steps are recommended:

(1) Establishment of an imaging working group to refine the vision and define the near and long term strategic goals. Membership should include appropriate Agency mission directorate representatives and the NASACommercial Crew Development office along with experts within DoD, industry and academia. Identify collaborative opportunities between Science Mission Directorate (SMD), Fundamental Aeronautics Program in the Aeronautics Research Mission directorate (ARMD), International Space Station Utilization in the Space Operations Mission Directorate (SOMD), and entry, descent and landing technology development in the Exploration Systems Mission Directorate (ESMD) and the Office of Chief Technologist (OCT), Commercial Crew and Cargo Office (ESMD), Commercial Crew Development (ESMD), Multi Purpose Crew Vehicle (ESMD) and the Space Launch System (ESMD) and needs of other government agencies (U.S. Navy, U.S. Air Force, Missile Defense Agency).

(2) Perform an independent assessment study to baseline current imaging technology capabilities for spatially and spectrally resolved imagery along with current hardware/software capabilities and limitations. In addition, the assessment study shall identify baseline market forces, mission requirements and methods for improving operating costs. 
(3) Development of a technology roadmap to identify technology gaps and specific requirements for the development of a next generation autonomously controlled sensor/platform system. Formulation of a technology development plan to close the gaps will be required.

(4) Development of a technology development plan. Identify candidate sensor and image processing technology. Technologies of interest include (but are not limited to): system simulation software; advanced high resolution focal plane array development including multi-color focal plane arrays; large apertures; miniaturization of high frame rate multi-waveband (i.e., visible, NIR, SWIR, MWIR, LWIR) including spectral/hyperspectral sensors; advanced radiometric simulation software; real time imaging processing and post processing; deconvolution algorithms; adaptive optics; target recognition and low latency tracking algorithms; active feedback for platform command and control functions and local navigation and communication. Subsequent activities would include component and system verification in accordance with the roadmap, leading to the development of a prototype system.

(5) Demonstration of incremental technology advancements through the use of existing crewed aircraft within the NASA or DoD. Demonstrations performed in a spiral manner to develop and screen new sensor concepts and algorithm development for future implementation. Existing unmanned aerial system platforms such as the Global Hawk operated by NASA could be used in an incremental approach to demonstrate capability while reducing risk prior to committing to a fully autonomous next generation integrated imagery system. While the benefits of deploying a sensor at altitudes above weather and water vapor are clear, designing the payload in a modular fashion could permit integration with a ground-based optical system if warranted.

\section{Acknowledgments}

The authors would like to acknowledge the ambitious and dedicated work of numerous organizations and individuals that set the stage for this visionary look forward. Special recognition is extended to Dr. Peter Jenniskens of the SETI Institute who led the science team associated with the Hayabusa breakup imagery presented in this paper. The authors gratefully acknowledge all for their contributions and behind-the-scenes work.

\section{References}

${ }^{1}$ Horvath, T. J., Tomek, D. M., Berger, K. T., Zalameda, J. N., Splinter, S. C., Krasa, P. W., Schwartz, R. j., Gibson, D. M., Tietjen, A. B., Tack, S., "The HYTHIRM Project: Flight Thermography of the Space Shuttle During Hypersonic Re-entry," AIAA2010-241, January 2010.

2 Tack, S., Tomek, D. M., Horvath, T. J., Verstynen, H. A., and Shea, E. J., "Cast Glance Near Infrared Imaging Observations of the Space Shuttle during Hypersonic Re-entry," AIAA Paper 2010-243, Jan. 2010.

3 Zalameda, J. N., Horvath, T. J., Tomek, D. M., Tietjen, A. B., Gibson, D. M., Taylor, J. C., Tack, S., Bush, B. C., Mercer, C. D., and Shea, E. J., "Application of a Near Infrared Imaging System for Thermographic Imaging of the Space Shuttle during Hypersonic Re-entry," AIAA Paper 2010-245, Jan. 2010.

4 Gibson, D. M., Spisz, T. S., Taylor, J. C., Zalameda, J. N., Horvath, T. J., Tomek, D. M., Tietjen, A. B., Tack, S., and Bush, B. C., "HYTHIRM Radiance Modeling and Image Analyses in Support of STS-119, STS-125, and STS-128 Space Shuttle Hypersonic Re-entries," AIAA Paper 2010-244, Jan. 2010.

5 Wood, W. A., Kleb, W. L., Tang, C. Y., Palmer, G. E., Hyatt, A. J., Wise, A. J., McCloud, P. L., “Comparison of CFD Predictions with Shuttle Global Flight Thermal Imagery and Discrete Surface Measurements," AIAA Paper 2010-454, Jan. 2010.

${ }^{6}$ Spisz, T. S., Taylor, J. C., Gibson, D. M., Kwame, O. W., Horvath, T. J., Zalameda, J. N., Tomek, D. M., Berger, Tietjen, A. B., Tack, S., and Schwartz, R. J., "Processing near-infrared imagery of hypersonic space shuttle reentries," Thermosense XXXII Conference at 2010 SPIE Defense, Security, and Sensing Symposium, 5-9 April 2010, Orlando, FL, Paper 7661-17

7 Schwartz, R. J., McCrea, A. C., Gruber, J. R., Hensley, D. W., Verstynen, H. A., Oram, T., Berger, K. T., Splinter, S., Horvath, T. J., and Kerns, R. V., "Remote Infrared Imaging of the Space Shuttle During Hypersonic Flight: HYTHIRM Mission Operations and Coordination," AIAA Paper 2011-xxx, June 2011 (submitted for publication).

8 Taylor, J. C., Gibson, D. M., Spisz, T. S., and Horvath, T. J., "Global Thermography of the Space Shuttle during Hypersonic Re-entry," AIAA Paper 2011-xxx, June 2011 (submitted for publication).

9 Horvath, T. ., Berry, S. ., Alter, S., Blanchard, R., Schwartz, R., Ross, M., and Tack, S., "Shuttle Entry Imaging Using Infrared Thermography," AIAA-2007-4267, June 2007

${ }^{10}$ Horvath, T., Berry, S., Splinter, S., Daryabeigi, K., Wood, W., Schwartz, R., and Ross, M., “Assessment and Mission Planning Capability For Quantitative Aerothermodynamic Flight Measurements Using Remote Imaging," AIAA-2008-4022, June 2008. 
11 Berry, S., Horvath, T., Schwartz, R., Ross, M., Campbell, C., Anderson, B., "IR Imaging of Boundary Layer Transition Flight Experiments," AIAA-2008-4026, June 2008.

12 Hallion, R. P., "The History of Hypersonics: or, "Back to the Future - Again and Again"," AIAA Paper 2005-329, Jan. 2005.

13 Blankson, I. M., and Pyle. J. S., "NASA’s Hypersonic Flight Research Program”," AIAA Paper 1993-0308, Jan. 1993.

14 Schuster, D. M., NASA Aerosciences Perspective on Proposed De-Scope of Ares I-X Developmental Flight Instrumentation," NESC TI-08-00454, Feb., 2008.

${ }^{15}$ Warwick, G., "Darpa, AFRL Prepare To Restage Hypersonic Test Flights,” Aviationweek.com, May, 2011.

${ }^{16}$ Walker, S. H., Sherk, J., Shell, D., Schena, R., Bergmann, J., and Gladbach, J., "The DARPA/AF Falcon Program: The Hypersonic Technology Vehicle \#2 (HTV-2) Flight Demonstration Phase,” AIAA Paper 2008-2539, April 2008.

17 Adler, M., Wright, M., Campbell, C., Clark, I., Engelund, W., and Rivellini, T., "Draft Entry, Decent and Landing Roadmap," Technology Area 09, 2011, (http://www.nasa.gov/offices/oct/home/roadmaps/index.html).

18 Page, R., "NASA Imagery Planning in Support of Space Flight,” Unpublished white position paper, May 2006.

19 Iannotta, B., "Seeing stars with SOFIA," Aerospace America, June, 2002.

20 Ballistic Missile Defense Review Report, Feb., 2010.

21 Missile Defense Agency Fiscal Year (FY11) Budget Estimates, 10-MDA-5141, Jan. 2010.

22 Ross, M., Toohey, D., Peinemann, M., and Ross, P., "Limits on the Space Launch Market Related to Stratospheric Ozone Depletion," Astropolitics, 7: 1, pp. 50-82, 2009.

23 Tietjen, A. B., Emory, J., wendt, J., "High -Resolution mid-IR Measurements of Atlas in Boost Phase," Proc. IRIS Specialty Group on Targets, Background and discrimination. 1996.

24 Goldberg, A. C., Tietjen, A. B., "Observation of the Launch Phase of an Atlas V EELV with a Dual-Band QWIP focal Plane Array,” Infrared Spaceborne Remote Sensing XI, Proc., SPIE 5152, pp. 100-144, 2003.

25 Personal communication with Martin Ross, Aerospace Corporation and Alan Tietjen, ISTEF.

26 Berry, S. A., Horvath, T. J., Greene, F. A., Kinder, G. R., and Wang, K.C., "Overview of Boundary Layer Transition Research in Support of Orbiter Return to Flight," AIAA-2006-2918, June 2006.

27 Berry, S. A., Kimmel, R., and Reshotko, E., "Recommendations for Hypersonic Boundary Layer Transition Flight Testing," AIAA Paper 2011-xxx, June, 2011 (submitted for publication).

28 Ross, M., "Time to Get Serious About Rocket Emissions," Space News, June 8, 2009, p.27.

29 Johnston, C., "Potential for Validation of NASA Aerothermodynamic Tools Using Instrumented Meteor Observations," Unpublished white position paper, May 2011.

30 Ailor, W., and Womack, J., "Effects of Space Debris on the Cost of Space Operations," IAC-10.A6.10, Oct., 2010.

31 Ailor, W., Hallman, W., Steckel, G., and Weaver, M., “Analysis of Reentered Debris and Implications For Survivability Modeling," Proceedings of the 4th European Conference on Space Debris, Darmstadt, Germany, 18-20 April 2005.

32 Taylor, A., Kelly, C., Magner, E., Peterson, D., Hahn, D. and Yuchnovicz, D., “A Review of the NASA MLAS Flight Demonstration," AIAA Paper 2011-2586 May 2011.

33 Jenniskens, P., Wercinski, P., Oleijniczak, J., Raiche, G., Kontinos D., Allen, G., Desai, P. N., Revelle, D., Hatton, J., Baker, R. L., Russell, R. W., Taylor, M., Rietmeijer, F., "Preparing for Hyperseed MAC: an observing campaign to monitor the entry of the Genesis Sample Return Capsule", Earth, Moon, and Planets, Vol. 95, pp. 339-360.

34 Jenniskens, P., Wercinski, P. F., Olejniczak, J., Wright, M., Raiche, G., Kontinos, D., Desai, P. N., Spalding, R. E., Sandquist, K., Rossano, G., Russell, R. W., Revelle, D. O., Hladiuk, D., and Hildebrand, A. R., "Surface Heating from Remote Sensing of the Hypervelocity Entry of the NASA Genesis Sample Return Capsule," AIAA Paper 2006-0381, Jan. 2006.

35 Jenniskens, P., "Observations of the STARDUST Sample Return Capsule Entry with a Slit-less Echelle Spectrograph," AIAA Paper 2008-1210, Jan., 2010.

36 Stardust Hypervelocity Entry Observing Campaign Support," NASA Engineering and Safety Center Rept. RP-06-80, 31 Aug. 2006.

37 Jenniskens, P., "Observations of the Stardust Sample Return Capsule Entry with a Slitless Echelle Spectrograph", Journal of Spacecraft and Rockets, Vol. 47, No. 6, pp. 718-735, 2010.

38 Liu, Y., Prabhu, D., Trumble, K. A., Saunders, D., and Jenniskens, P., "Radiation Modeling for the Reentry of the Stardust Sample Return Capsule", Journal of Spacecraft and Rockets, Vol. 47, No. 6, pp. 741-752, 2010.

39 Rairden, R. L., and Jenniskens, P., "Near-Ultraviolet Spectroscopy of the Stardust SRC Reentry", Journal of Spacecraft and Rockets, Vol. 47, No. 6, pp. 753-756, 2010. 
AIAA 2011-xxx

${ }^{40}$ Trumble, K. A., Cozmuta, I., Sepka, S., Jenniskens, P., and Winter, M., "Postflight Aerothermal Analysis of Stardust Sample Return Capsule", Journal of Spacecraft and Rockets, Vol. 47, No. 6, pp. 765-774, 2010.

41 Harms, F., Wolf, J., Raiche, G., and Jenniskens, P., "Imaging and Slitless Spectroscopy of the Stardust Capsule Reentry Radiation”, Journal of Spacecraft and Rockets, Vol. 47, No. 6, pp. 868-872, 2010.

42 Jenniskens, P., Wilson, M. A., Winter, M., and Laux, C. O., " Resolved CN Band Profile of Stardust Capsule Radiation at Peak Heating”, Journal of Spacecraft and Rockets, Vol. 47, No. 6, pp. 873-877, 2010.

43 Taylor M. J., and Jenniskens, P., "Near-Infrared Spectroscopy of the Stardust Sample Return Capsule Entry: Detection of Carbon", Journal of Spacecraft and Rockets, Vol. 47, No. 6, pp. 878-883, 2010.

44 Stenbaek-Nielsen, H. C. and Jenniskens, P., "High-Speed Spectrographic Photometry of the Stardust Sample Return Capsule around Peak Deceleration”, Journal of Spacecraft and Rockets, Vol. 47, No. 6, pp. 884-888, 2010.

${ }^{45}$ Wercinski, P. F., and Jenniskens, P., "Digital Still Snapshots of the Stardust Sample Return Capsule Entry", Journal of Spacecraft and Rockets, Vol. 47, No. 6, pp. 889-894, 2010.

46 Jenniskens, P., Koop, M., and Albers, J., "Intensified Low-Resolution Optical Spectroscopy of the Stardust Sample Return Capsule Entry", Journal of Spacecraft and Rockets, Vol. 47, No. 6, pp. 895-900, 2010.

${ }^{4}$ Winter, M. W., and Trumble, K. A., "Near-Ultraviolet Emission Spectroscopy During an Airborne Observation of the Stardust Reentry", Journal of Spacecraft and Rockets, Vol. 48, No. 1, pp. 59-71, 2011.

48 Grinstead, J. H., Jenniskens, P., Cassell, A. M., Albers, J., and Winter, M. W., "Airborne Observation of the Hayabusa Sample Return Capsule Re-entry", AIAA Paper 2011-xxx, June 2011 (submitted for publication).

49 Cassell, A. M., Allen, Jr., G. A., Grinstead, J. H., Antimisiaris, M., Albers, J., and Jenniskens, P., "Hayabusa Reentry: Trajectory Analysis and Observation Mission Design", AIAA Paper 2011-xxx, June 2011 (submitted for publication).

50 De Pasquale, E., Francillout, L., Wasbauer, J-J., Hatton, J., Albers, J., and Steele, D., “ATV Jules Verne Reentry Observation: Mission Design and Trajectory Analysis," 30 $0^{\text {th }}$ IEEE Aerospace Conference, Paper \#1155, Mar. 2009.

51 Grossman, E., “Army Eyes Advanced Hypersonic Weapon,” Military.com, Jan., 2007.

52 Norris, G., "Inquiry Begins Into Hypersonic Missile Failure,” Aviation Week \& Space Technology, Feb., 2008.

53 "SpacePlane Flight Reset," Aviation Week \& Space Technology, Sept., $28,2009$.

54 Borg, M., Schneider, S., and Juliano, T., " Effect of Freestream Noise on Roughness-Induced Transition for the X-51A Forebody," AIAA-2008-592, Jan., 2008.

55 Tumino, G., Basile, L., and Angelino, E., “The IXV Project from Design to Development,” IAC-09 - D2.6.03, 2009.

56 Reibaldi, G., Gavira, J., et. al., "EXPERT: The ESA Experimental Re-entry Test-Bed Programme,” IAC-08 - D2.6, 2008.

57 Dolvin, D., "Hypersonic International Flight Research and Experimentation (HIFiRE) Fundamental Sciences and Technology Development Strategy", AIAA-2008-2581, April-May, 2008.

58 Norris, G., Aviationweek.com, May 2011.

59 Butler, A., “MDA Eyes Missile Detecting Infrared Pod,” Aviationweek.com, April 2010. 